\title{
Intracellular reactive oxygen species scavenging activity and lipid peroxidation inhibition by secondary metabolites isolated from the endophytic fungus, Daldinia eschscholtzii
}

Shazia Anjum Musthafa

SRM Institute of Science and Technology

Muhammad Sadiq

SRM Institute of Science and Technology

Kesavan Muthu

SRM Institute of Science and Technology

Saraniya Sekar

SRM Institute of Science and Technology

Dhamodharan Umapathy

Saveetha University Saveetha Dental College

GANESH MUNUSWAMY-RAMANUJAM ( $\sim$ mrganesh2000@hotmail.com )

SRM Institute of Science and Technology https://orcid.org/0000-0001-8021-601X

\section{Research Article}

Keywords: Endophyte, Daldinia eschscholtzii, secondary metabolites, Gossypetin-3'-0-glycoside, Antioxidants

Posted Date: April 6th, 2021

DOI: https://doi.org/10.21203/rs.3.rs-391337/v1

License: (c) (i) This work is licensed under a Creative Commons Attribution 4.0 International License. Read Full License 


\section{Abstract}

Fungal endophytes associated with medicinal plants are of research interests, since they provide a viable alternative source for molecules with medicinal value. In this study, we report for the first time two fungal endophytic isolates, Al.EF 001 and Al.EF 002 belonging to the genus Daldinia from the leaves of medicinal plant, Abutilon indicum linn (Al). Both Al.EF were identified as Daldinia eschscholtzii (DE) species by ITS1-5.8-ITS2 sequence analysis and phylogenetic tree reconstruction by Neighbor-joining method. Crude extracts of DE (EFEA), generated by ethylacetate/water fractionation of the fungal methanol extracts when subjected to column chromatography separation yielded 5 compounds. NMR

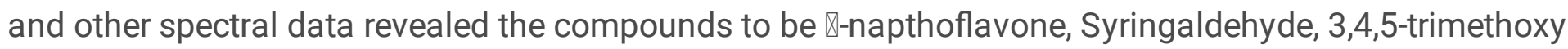
benzoic acid, 2-Furoic acid and Gossypetin 3' 0 glycoside. All of these compounds are being reported for the first time from $D E$. The isolated compounds showed promising free radical scavenging activities. The compounds also exhibited anti inflammatory property by down regulating intracellular ROS as well as inhibiting LPS induced lipid peroxidation in AtT 20 mouse pituitary cells. Current finding demonstrates endophyte DE as a new source for the flavanoid, Gossypetin-3'-0-glycoside along with other phytoconstituents with strong antioxidant and anti-inflammatory activity.

\section{Introduction}

Endophytes are microorganisms that colonize inside the plant and form an important component in the plant-micro ecosystem. They reside in the tissue of plants in a symbiotic fashion without causing any negative impact on the host (Chatterjee et al. 2019). Endophytes mostly belong to the class Ascomycetes, Basidiomycetes and Deuteromycetes, forming a considerable proportion of the fungal species (Padhi et al. 2013). This makes endophytes a promising alternative source for mining of compounds with novel therapeutic molecules. Metabolites from endophytes have shown potential applications in agriculture, industries and in modern medicine as antibiotics, antimycotics, immunosuppressant and anticancer compounds ( $\mathrm{Jia} \mathrm{M}$ et al. 2016). Added advantage of utilizing endophytic fungi as a source for obtaining phytochemicals is, it helps to conserve the plant biodiversity. Since, endophytes mimic metabolites found in the host plant and can provide an alternative source for the same (Mollaei S et al. 2019). This also makes endophytes an attractive target for commercial utilization. Overall, endophytes serve as a better source for the increasing demand of biologically active drugs in an environmentally friendly process (Gupta D et al. 2014).

Abutilon indicum linn (Al) commonly known as thuthi is an important medicinal plant belonging to the family Malvaceae. In traditional system of medicine, the plant is used as a cure for human ailments like ulcers, piles, anxiety and as diuretic (Suryawanshi V.S and S.R Umate 2020). A number of bioactive secondary metabolites derived from this plant like beta sitosterol, caffeic acid, gallic acid, flavonoids, saponins, alkaloids have been reported. Earlier reports indicate that, the plant possesses hepatoprotective, anti-inflammatory, anti-fungal, wound healing and anti-bacterial properties (Sharma et al. 2013). A few strains of endophytic fungi like Alternaria alternata, Aspergillus niger, Nigrospora sp, Cladosporium sp, Fusarium sp has been previously reported in this plant (Mahobiya D and Gupta A.K 
2017; Suryanarayanan et al. 2007). Considering that extracts of Al is already in use as traditional medicine, it could be hypothesized that metabolites of endophytic fungi from Al could be of potential medicinal value.

Inflammation is a major factor for the progression of various chronic disorders and these inflammatory disorders, in turn show correlation to the presence of free radicals in the biological system. Increase in free radicals leads to oxidative damage of the functional macromolecules, which is a precursor for increased expression of inflammatory cytokines. Hence, antioxidant compounds that are efficient in reducing the free radical levels are shown to have a significant effect on reducing inflammation, leading to the amelioration of inflammatory disorders (Hussain et al. 2016). One of the major pathways involved in the oxidative stress mediated inflammation is the lipid peroxidation. In this pathway, lipid macromolecules are oxidized to toxic lipid aldehydes by the free radicals. The chief instigators of lipid peroxidation are hydroxyl radical $\left(\mathrm{OH}^{-}\right)$, superoxide radical $\left(\mathrm{O}_{2}^{-}\right)$, hydrogen peroxide $\left(\mathrm{H}_{2} \mathrm{O}_{2}\right)$, and nitric monoxide $\left(\mathrm{NO}^{-}\right)$. When present in excess, these oxidative species readily attack cellular lipid membrane resulting in their oxidative degradation. This leads to cellular and tissue damages, inflammation and cell death (Chang Y and Kim C.Y 2018). Identifying compounds which in general target ROS or specifically prevents lipid peroxidation will be a valuable tool in our fight against inflammatory disorders. In this scenario, investigating the antioxidant ability of metabolites from endophytic fungi isolated from established medicinal plants could be of interest. Recent studies have shown that fungal metabolities, 3methoxy flavone, Nobelitin, Scopoletin and Formononetin have been isolated from endophytic fungal strain CBL 12. The endophytic fungus was isolated from the medicinal plant, Conyza blinii H.Lev. (Tang et al. 2020). Apart from this, Quercetin, a flavonoid has been reported from endophytic fungus, Psathyrella candolleana and Apigenin 8-C- $\beta$-D glucopyranoside from Colletotrichum sp (Toghueo 2020). Similarly, a flavone, Chrysin (5,7 dihydroxy flavone) from endophytic fungi $A$. alternate, C.capsici and C.taiwanense with anticancer property has been reported (Seetharaman et al. 2017). These studies clearly highlight the potential of endophytic fungi as a rich source of antioxidant metabolites like flavonoids, with the added advantage of large scale microbial mass cultivation and production.

In the present study, attempts were made to isolate and identify new endophytic fungal species from the leaves and pods of Al. In the process, a noteworthy species of Daldinia was identified from leaf tissues whereas the pods did not show any presence of endophyte colonization. Literature search indicates that as on date there is no known report of DE from any parts of Al. Also, this study is evidenced by detailed morphological, molecular and phenotypic characterization. Further, attempts were made to characterize the bioactive fractions and identify the major metabolites and to investigate the inhibitory activity of the bioactive compounds on lipid peroxidation and ROS generation.

\section{Materials And Methods}

\section{Collection of Al plant materials}


Healthy mature leaves and pods from 2 different plants of Al were collected from Potheri, Tamilnadu during the month of November. The whole plant was identified and authenticated (Reg. No.

PARC/2019/3951) by Prof. P.Jayaraman, Plant Anatomy Research Centre where the voucher specimen has been deposited.

\section{Isolation of Endophytic fungi from leaves and pods of Al}

Endophytic fungi were cultured from the leaves (2 nos.) and pods ( 2 nos.) after appropriate surface sterilization of the plant parts. Surface sterilization protocol was carried out according to the method described by Pedra et al (2018) with minor modifications. Fresh leaves and pods were washed thoroughly in running tap water, and then surface sterilized with 4\% hypochlorite for 2-3 minutes and washed 3 times with autoclaved distilled water. The plant samples were further washed with $70 \%$ ethanol and allowed to air dry before further processing. The leaves were excised into small pieces $(0.5 \mathrm{~cm} \times 0.5 \mathrm{~cm})$ using a sterile scalpel and placed on potato dextrose agar plates (PDA: $300 \mathrm{~g} / \mathrm{L}$ diced potatoes, $20 \mathrm{~g} / \mathrm{L}$ dextrose and $20 \mathrm{~g} / \mathrm{L}$ agar under sterile conditions. Similarly, a single leaflet from the pods were excised and placed on to the agar plates. 4 leaf and pod segments were placed on each plate. $50 \mu \mathrm{g} / \mathrm{ml}$ of chloramphenicol was added to the media to prevent bacterial growth. The samples were incubated for $5-$ 7 days at $28^{\circ} \mathrm{C}$. The fungal hyphae emerging from the leaves were sub cultured in PDA and the pure cultures were kept as PDA slants at $4^{\circ} \mathrm{C}$ for further studies. After final identification of the endophytic fungi as $D E$, the results were further confirmed by plating the leaf samples in Oatmeal agar $(O A: 60 \mathrm{~g} / \mathrm{L}$ oatmeal and $12.5 \mathrm{~g} / \mathrm{L}$ Agar)

\section{Identification of the isolated Endophytic fungi Morphological Analysis}

The isolated endophytic fungi were identified based on the morphological characteristics. Morphological features such as color, texture and topography of the isolates were examined on PDA and OA. The cultures were incubated at $30^{\circ} \mathrm{C}$ with day to day examination of fungal growth. Morphological analysis was done by staining the isolates with lactophenol cotton blue as previously described by Kuan et al (2015). The stained fungi were observed and imaged using fluorescent microscope -BF (Zeiss, Germany) at $100 \mathrm{X}$ magnification. The ZEN 10 software was used to process the images.

\section{DNA extraction}

Pure fungal mycelia were harvested carefully from the agar surface using a sterile forceps. These mycelia were transferred aseptically to sterile phosphate buffered saline $(\mathrm{pH} \mathrm{7.4)}$ and vortexed with glass beads for 5 minutes. $200 \mu$ l of lysate was subjected to DNA extraction using DNeasy Plant Mini kit, Qiagen, USA, according to the manufacturer's protocol. The extracted DNA samples were quantified and their quality confirmed using nanodrop for further sequencing analysis.

\section{PCR amplification and DNA sequencing}


DNA isolated from the endophytic fungi was diluted in sterile water and stored at $4^{\circ} \mathrm{C} . P C R$ was performed using the primersF:5'AATCAGTTATAGTTTATTTGATGGTGGT3',

R:3'TCTCAGGCTCCCTCTCCGGAACC5'. The reaction was performed in a $25 \mu$ final volume containing $0.1 \mu \mathrm{g}$ of genomic DNA, $10 \mathrm{pM}$ of each primer, $1 \mathrm{X}$ Taq.pol buffer, $1.5 \mathrm{mM} \mathrm{Mgcl}_{2}, 0.2 \mathrm{mM} \mathrm{dNTPs}$ and $1 \mathrm{U}$ Taq DNA polymerase. Thermal parameters used for the PCR was, $94^{\circ} \mathrm{C}(3 \mathrm{~min})$ followed by 35 cycles with following parameter executed in each cycle, $94^{\circ} \mathrm{C}(30 \mathrm{~s}), 55^{\circ} \mathrm{C}(40 \mathrm{~s})$ and $72^{\circ} \mathrm{C} \mathrm{(35s)} \mathrm{and} \mathrm{a} \mathrm{final} \mathrm{extension}$ at $72^{\circ} \mathrm{C}(7 \mathrm{~min}) . \mathrm{PCR}$ amplified products were examined by electrophoresis in $1.5 \%$ agarose gels in TAE buffer and purified using a PCR clean-up kit (QIAquick PCR Purification Kit, Qiagen, USA). The purified PCR products were sequenced using the Nextseq 500 DNA Analyzer. As an underlying basis to identify the fungi, the sequences were manually edited and compared with available data from Genbank databases (NCBI website; http://www.ncbi.nlm.nih.gov/) using the BLASTN program.

\section{Phylogenetic analysis}

rDNA-ITS sequences from the fungal endophyte strains (AI.EF 001, Al.EF 002) were submitted to GenBank and accession numbers were obtained. Fungal rDNA-ITS sequences along with the closely identified sequences obtained from GenBank based on the BLAST search were used for phylogenetic analysis to identify the endophytes (Samarakoon S, 2019). A total of 67 closely related sequences were obtained, out of which 10 sequences were used for phylogenetic reconstruction. Original sequences chromatogram was edited using chromas version 2.6 .6 software (Technelysiumpty Itd) and aligned using the Clustal W version 1.8 program. Phylogenetic tree was constructed using neighbor-joining $(\mathrm{NJ})$ algorithm with Hypoxylon fragiforme as outgroup. $\mathrm{NJ}$ analysis was done using MEGA version 10.1.8 software with bootstrap values calculated for 1000 replicate runs.

\section{Mass cultivation of Endophytic Fungi}

Isolated strains of endophytic fungi were grown in Potato dextrose broth (PDA: 300g/L diced potatoes and $20 \mathrm{~g} / \mathrm{L}$ dextrose). $8 \mathrm{~mm}$ discs of the fully grown fungal mycelium was punched with the cork borer and inoculated aseptically to the broth in $500 \mathrm{ml}$ Erlenmeyer's flasks (15 nos) each containing $200 \mathrm{ml}$ of PDA broth. The cultures were grown for a period of 21 days (Yang et al. 2017) at $28^{\circ} \mathrm{C}$ in a shaker incubator under constant shaking (200 rpm).

\section{Preparation of crude extracts}

Al.EF cultures (Al.EF 001 and Al.EF 002) were collected by filtering on WhattmanNo.1 filter paper and air dried using a Buchner funnel. Fungal mycelia were weighed (Al.EF 001-800 g, Al.EF 002-715 g) and extracted with methanol. Extraction was repeated 3 times $(24 \mathrm{~h})$ with equal volume of methanol $(1000 \mathrm{ml})$. Al.EF methanolic extracts were filtered through Whattman No.1 filter paper, pooled and evaporated under vacuum. Dried Al.EF extracts were further partitioned (3 times) between equal volumes of ethylacetate $(E A)$ and water $(300 \mathrm{ml})$ using a separating funnel. Obtained EA fractions were pooled, dried over anhydrous sodium sulphate and evaporated under vacuum to yield Al.EF ethylacetate fractions (EFEA 001-4.8 $\mathrm{g}$ and EFEA 002-3.9 g) 


\section{Preliminary Phytochemical screening of crude extracts}

The fungal extracts were analyzed for the presence of phytochemical compounds according to the method described by Rahman et al (2017) with minor modifications

\section{Test for Flavonoids}

Alkaline Reagent test $-2 \mathrm{ml}$ of $2 \% \mathrm{NaOH}$ was mixed with crude EFEA. Appearance of concentrated yellow colour indicates the presence of flavonoids.

\section{Test for Tannins}

$10 \mathrm{ml}$ of bromine water was added to $0.5 \mathrm{ml}$ of EFEA. De colouration of bromine water shows the presence of tannins.

\section{Test for Steroids}

$2 \mathrm{ml}$ of $\mathrm{CHCl}_{3}$ and conc. $\mathrm{H}_{2} \mathrm{SO}_{4}$ were added to $0.5 \mathrm{ml}$ of EFEA. Appearance of red colour in the $\mathrm{CHCl}_{3}$ layer indicated the presence of steroids.

\section{Test for Glycosides}

Keller-kiliani Test- $4 \mathrm{ml}$ of glacial $\mathrm{CH}_{3} \mathrm{COOH}$ and 1 drop of $2 \% \mathrm{FeCl}_{3}$ was mixed with $1 \mathrm{ml}$ of EFEA and then $1 \mathrm{ml}$ of conc. $\mathrm{H}_{2} \mathrm{SO}_{4}$ was added slowly. Appearance of brown ring shows the presence of glycosides.

\section{Test for Terpenoids}

$2 \mathrm{ml}$ of chloroform was added with $0.5 \mathrm{ml}$ of EFEA and then boiled with $3 \mathrm{ml}$ of conc. $\mathrm{H}_{2} \mathrm{SO}_{4}$. The formation of grey colour shows the presence of terpenoids.

\section{Test for Saponins}

This test was carried out by the method described by Ejikeme et al (2014) with minor modifications. Distilled water $3 \mathrm{ml}$ was added to $0.3 \mathrm{ml}$ of EFEA and boiled for 10 minutes in water bath and filtered using Whatman filter paper number $(125 \mathrm{~mm})$. A mixture of distilled water and filtrate was agitated vigorously for a stable persistent froth. The formation of emulsion on addition of three drops of olive oil showed the presence of saponins

\section{Cytotoxic assay of EFEA extracts}

\section{Chemicals}

Fetal Bovine Serum (FBS), Phosphate Buffered Saline (PBS),Dulbecco modified Eagles medium (DMEM) and Trypsin was obtained from Sigma Aldrich Co, St Louis, USA.EDTA, Glucose and antibiotics from Hi- 
Media Laboratories Ltd., Mumbai.

\section{Cell lines and culture medium}

Mouse pituitary cell lines AtT20 were procured from National Centre for Cell Sciences (NCCS), Pune, India. Cells were cultured in DMEM supplemented with $20 \%$ inactivated Fetal Bovine Serum (FBS), Penicillin $(100 \mathrm{lU} / \mathrm{ml})$, Streptomycin $(100 \mathrm{mg} / \mathrm{ml})$ and Amphotericin B $(5 \mathrm{mg} / \mathrm{ml})$ in a humidified atmosphere of $5 \%$ $\mathrm{CO}_{2}$ at $37^{\circ} \mathrm{C}$ until confluent.

\section{Determination of cell viability of EFEA fractions}

EFEA 001 and 002 were tested on AtT20 cell lines and cell viability was assessed using PI staining with the aid of flow cytometry (FACS) (BD FACS calibur) (Ramachandran et al, 2018). AtT20 cells $(20,000$ cells $/ \mathrm{ml})$ were seeded and incubated for $18 \mathrm{hrs}$ with EFEA $(2.5 \mathrm{mg} / \mathrm{ml}-0.15 \mathrm{mg} / \mathrm{ml})$ or Doxorubicin (positive control, $0.1 \mathrm{mg} / \mathrm{ml}$ ). At the end of incubation, the cells were centrifuged, pelleted, re suspended in FACS buffer and stained with PI $(10 \mu \mathrm{l}$ of $1 \mathrm{mg} / \mathrm{ml})$ for $10 \mathrm{~min}$ in the dark. Viability of cells was assessed using FACS - FL2 detector and analyzed using BD CELLQUESTPRO software.

\section{Fractionation and purification of compounds from EFEA using Column chromatography}

Preliminary TLC investigation of EFEA 001 and 002 revealed a similar molecular profile with few exceptions. Both EFEA were subjected to silica gel column chromatography for isolation of compounds. $4.8 \mathrm{~g}$ of EFEA was loaded on to the packed column as admixture ( $4.8 \mathrm{~g}$ of silica). Silica gel $\mathrm{G}(60-120$ mesh, $69 \mathrm{~g}$ ) in hexane was used to pack the column. Increasing volume of EtOAc in Hexane was used as eluent. Fractions were monitored with TLC and those containing similar compound profiles were pooled, solvent evaporated under vacuum and weighed. Since EFEA 002 showed a similar compound profile as EFEA 001 with some exceptions, EFEA 002 was also subjected to similar column chromatography separation and the compounds isolated. The isolated compounds were characterized using standard spectroscopic techniques.

\section{Spectroscopic Characterization of isolated compounds}

EFEA 001 yielded 5 compounds (C1-C5) and EFEA 002 yielded 3 compounds (C1, C3 and C4) which were characterized using NMR, UV, IR and Mass spectrometry. UV characterization was done by dissolving compounds (C1- C5) in methanol (10 $\mu \mathrm{g} / \mathrm{ml})$ and analyzing them for maximum absorbance using UV-VIS spectrophotometer (Shimadzu). FT-IR analysis for the isolated compounds was carried out in $\mathrm{KBr}$ pellets using Bruker alpha-E\&T spectrophotometer (Lab India). ${ }^{1} \mathrm{H},{ }^{13} \mathrm{C}, \mathrm{HMBC}$ and HSQC spectra were recorded with the aid of NMR (500 MHz - BRUKER) using tetramethylsilane (TMS) as an internal standard. NMR for compounds $\mathrm{C} 1-\mathrm{C} 3$ was carried out in $\mathrm{CDCl}_{3}$ while compounds $\mathrm{C} 4$ andC5 were dissolved in $\mathrm{D}_{6}$-DMSO solvent. MS analysis was done using SHIMADZU mass spectrophotometer to determine the molecular mass of the isolated compounds.

\section{Quantification of compounds by HPTLC Technique}


Total amount of individual compounds (C1-C5) present in their respective EFEA crude fractions were quantified using HPTLC technique. Quantification was carried out using $8 \times 10 \mathrm{~cm}^{2} T L C$ plate (Merck, Germany) and CAMAG HPTLC analyzer. The suitable mobile phase for compounds 1-4 were chloroform, methanol, glacial acetic acid and n-butanol, acetic acid and water for compound 5. 6 ul of EFEA (30 $\mathrm{mg} / \mathrm{ml})$ and isolated compounds C1 $(7.5-125 \mu \mathrm{g} / \mathrm{ml}), \mathrm{C} 2-\mathrm{C} 5(60-1000 \mu \mathrm{g} / \mathrm{ml})$ were applied to the TLC plate using an automatic TLC applicator (Linomat 5). A linearity range of $60-1000 \mu \mathrm{g} / \mathrm{band}$ was maintained for the individual compounds. TLC plates were eluted using chloroform: methanol:acetic acid (9.6:0.2:0.2) as mobile phase for C1-C4 and n-butanol:aceticacid:water (4:2:4) for C5. TLC plates were imaged using CAMAG TLC visualizer and scanned using CAMAG TLC scanner ( $366 \mathrm{~nm}$ and $254 \mathrm{~nm}$ ). Quantification in EFEA was calculated by plotting concentration of individual compound to its peak area obtained from HPTLC chromatogram (CATS software).

\section{Determination of $\mathrm{IC}_{50}$ values of isolated compounds by MTT assay}

Isolated compounds (C1-C5) were tested on AtT20cell lines and cell viability was assessed using MTT assay as previously described by Shazia Anjum et al (2020) with minor modifications. 20000 cells per well were seeded in $1.5 \mathrm{ml}$ eppendorf tubes and treated with different concentrations of compounds C1C5 $(0.03 \mathrm{mg}-1 \mathrm{mg} / \mathrm{ml})$ and Doxorubicin $(0.1 \mathrm{mg} / \mathrm{ml})$ for $24 \mathrm{hrs}$. MTT $(5 \mathrm{mg} / \mathrm{ml})$ was added to the treated cells and incubation continued for $3 \mathrm{~h}$. The cells were then washed and MTT-Formazan complex was dissolved in Dimethyl Sulfoxide (DMSO). Absorbance was read at $570 \mathrm{~nm}$ using Thermo Multiskan go 96 well Microplate reader. Cell viability was determined as the relative percentage of treated cells to the untreated cells and the $\mathrm{IC}_{50}$ values are calculated.

\section{Antioxidant assays}

DPPH, ABTS, Superoxide anion and hydroxyl radical scavenging activity assay was carried out to identify the antioxidant potential of all the compounds. All these assays were carried out as triplicates with the compounds (C1-C5) evaluated within the concentration range of $(0.06-1.0 \mathrm{mg} / \mathrm{ml})$, using ascorbic acid as the positive control. The following formula was used to calculate the antioxidant activity:

Radical scavenging activity $(\%)=[($ Acontrol - Asample $) /$ Acontrol $] \times 100 \%$

\section{DPPH radical scavenging activity assay}

2,2-Diphenyl-1-picrylhydrazyl (DPPH) was used to determine the free radical scavenging activity of the isolated compounds (C1-C5) using colorimetric method with slight modification (Sannasimuthu A et al, 2018). Briefly, an aliquot of $100 \mu \mathrm{L}$ of individual compounds were mixed with $100 \mu \mathrm{L}$ of DPPH solution $(0.1 \mathrm{mM})$. The reaction mixture was incubated for $30 \mathrm{~min}$ at room temperature and its absorbance $(A)$ measured at $517 \mathrm{~nm}$ using a Thermo Multiskan go 96 well Microplate reader. The radical scavenging efficacy of the isolated compounds was determined as mentioned above

\section{ABTS Radical Scavenging Assay}


ABTS radical scavenging activity was done based on the method described by Sannasimuthu et al (2019) with slight modifications. Briefly, $7 \mathrm{mM}$ ABTS solution was mixed with $2.45 \mathrm{mM}$ potassium persulfate to produce $A B T S$ radical cation $\left(A B T S^{\circ}+\right)$. The reaction mixture was diluted to an absorbance of $0.70 \pm 0.02$ at $734 \mathrm{~nm}$ using $0.2 \mathrm{M} \mathrm{PBS}(\mathrm{pH} \mathrm{7.4})$ at $30^{\circ} \mathrm{C}$. $20 \mu \mathrm{L}$ of compounds were added to $180 \mu \mathrm{L}$ of diluted $\mathrm{ABTS}{ }^{\circ}+$ solution and incubated at $30^{\circ} \mathrm{C}$ for $6 \mathrm{~min}$. Decrease in absorbance at $734 \mathrm{~nm}$ was monitored using a spectrophotometer (UV1800, SHIMADZU, Kyoto, Japan). Concentration of the compounds giving the similar decrease of $\mathrm{ABTS}^{\circ}+$ cation as that of positive control was calculated using the formula as mentioned above.

\section{Superoxide anion radical scavenging activity assay}

The superoxide anion radical scavenging activity of the compounds was analyzed according to the method described by Chi et al (2014) with minor modifications. Briefly, superoxide anion radical was generated in 50 all of nitrotetrazolium blue chloride $(2.52 \mathrm{mM}), 50$ all of NADH $(624 \mathrm{mM})$ along with 50 all of compounds. This was followed by the addition of 50 all of phenazine methosulfate solution $(120 \mu \mathrm{g} / \mathrm{mL})$ to the reaction mixture. After incubation for $5 \mathrm{~min}$ at $25^{\circ} \mathrm{C}$, the absorbance of the product formed was read at $560 \mathrm{~nm}$ (UV1800, SHIMADZU, Kyoto, Japan). Ability of the compounds to scavenging superoxide anion radical was calculated using the formula mentioned above.

\section{Hydoxyl radical scavenging activity assay}

Hydroxyl radical scavenging activity was performed as described by Batool et al (2019) with minor modifications. Briefly, a mixture of $30 \mu \mathrm{L}$ of 1,10-phenanthroline $(5.0 \mathrm{mM}), 30$ all of EDTA $(15 \mathrm{mM})$ and 30 all of FeSO4 (5.0 mM) was mixed with 30 all of sodium phosphate buffer $(0.2 \mathrm{M}, \mathrm{pH} 7.4)$. This was followed by the addition of 40 all of compounds C1-C5 along with 40 all of Hydrogen peroxide $(0.03 \%)$ and incubated for $60 \mathrm{~min}$ at $37^{\circ} \mathrm{C}$. Finally, the absorbance of the solution was measured at $536 \mathrm{~nm}$ (UV1800, SHIMADZU, Kyoto, Japan). Radical scavenging activity was calculated in accordance with the formula as mentioned above.

\section{Intracellular ROS scavenging activity of the isolated compounds}

Intracellular Reactive Oxygen Species (ROS) was measured using DCFH-DA fluorescent dye in AtT 20 mouse pituitary cells using a standardized method with minor modifications (Ramachandran S et al, 2018). The cells were cultured in a 6 -well plate at a density of $7 \times 10^{4} \mathrm{cells} / \mathrm{well} / \mathrm{ml}$. Cells were treated with peroxide followed by the treatment of compounds $\mathrm{C} 1-\mathrm{C} 5$ at $\mathrm{IC}_{50}$ concentration as mentioned above. $\mathrm{H}_{2} \mathrm{O}_{2}$ alone treated cells were used as positive control and all the groups were incubated for $24 \mathrm{~h}$. At the end of incubation, the cells were exposed to $10 \mu \mathrm{M}$ of DCFH-DA at for $30 \mathrm{~min}$. Cells were then harvested and fluorescence intensity measured using BD FACS calibur (Ex/Em - $488 \mathrm{~nm} / 530 \mathrm{~nm})$. The analysis was done using BD Cell Quest Pro software.

\section{In vitro nitric oxide inhibitory activity}


Intracellular nitric oxide inhibition activity was measured in AtT20 cells according to the method described by Adebayo et al (2019) with some modifications. Briefly, 20,000 cells/well were seeded in 96 well plates followed by treatment with $50 \mu \mathrm{l}$ of compounds $\mathrm{C} 1-\mathrm{C} 5\left(\mathrm{IC}_{50}\right)$. After $2 \mathrm{hr}$ of incubation at $37^{\circ} \mathrm{C}$, $50 \mu \mathrm{l}$ of LPS $(5 \mu \mathrm{g} / \mathrm{ml})$ in DMEM was added to all wells containing the compounds. After $24 \mathrm{hrs}$ of incubation, the cells were collected and pelleted and the supernatants from cells were collected for NO measurement using colorimetric Griess reaction method.

$60 \mu$ l of supernatants were combined with equal volume of Griess reagent [ $1 \%$ sulphanilamide/ $0.1 \% \mathrm{~N}-(1-$ napthyl) ethylene diamine (International Laboratory, USA), each in $2.5 \% \mathrm{H}_{3} \mathrm{PO}_{4}$ ] in a 96 well plate at room temperature for 10 mins, and the absorbance was read at $550 \mathrm{~nm}$ using a Thermo Multiskan 96 well plate reader. Absorbance measurements were averaged and converted to $\mu \mathrm{mol} / \mathrm{L}$ of NO per well using a standard curve of sodium nitrite.

\section{In vitro Lipid peroxidation assay}

Lipid peroxidation assay is based on the production of malandialdehyde (MDA) in AtT20 cells as described by Hasanzadeh et al (2017) with some modifications. For evaluation of MDA production rate, thiobarbituric acid (TBARS) assay was used. 70,000 cells/well were seeded in a 12 well plate followed by treatment with $50 \mu$ l of compounds C $1-\mathrm{C} 5\left(\mathrm{IC}_{50}\right)$. After $2 \mathrm{hr}$ of incubation at $37^{\circ} \mathrm{C}, 50 \mu \mathrm{l}$ of LPS $(5 \mu \mathrm{g} / \mathrm{ml})$ in DMEM was added. After 24 hrs of incubation, the cells were collected and centrifuged at $1800 \mathrm{rpm}$ for $10 \mathrm{~min}$. The pellet was resuspended in $500 \mu \mathrm{l}$ of deionized water and lysed by sonication. $1 \mathrm{ml}$ of TBA solution ( $15 \%$ trichloroacetic acid, $0.8 \%$ thiobarbituric acid, $0.25 \mathrm{~N} \mathrm{HCl}$ ) was added. The mixture was heated at $95^{\circ} \mathrm{C}$ for $15 \mathrm{~min}$ to form MDA-TBA product. Optical density was measured at $532 \mathrm{~nm}$ spectrophotometrically.

\section{Statistical analysis}

Results obtained were analyzed and were then evaluated by analysis of variance (One-way and Two-way ANOVA). P-values less than $0.05(p<0.05)$ are considered to be significant.

\section{Results And Discussion}

Endophytic fungi ubiquitously inhabit most plant species and are recognized as a repository of novel compounds with immense applications. Added advantage of using the endophytic fungi is that they can be grown in a controlled environment in a sustainable manner to obtain secondary metabolites of medicinal value (Fouda A.H et al. 2015). Apart from this, endophytic fungi are also shown to mimic metabolites generated by the host plant. This makes exploration of endophytic fungi from traditional medicinal plants, a necessity for therapeutic advancements. In the present investigation, two fungal endophyte isolates (Al.EF 001, Al.EF 002) were isolated from the leaves of Al and were identified as Daldinia eschscholtzii (DE). Earlier reports indicate the presence of endophytic fungus Alternaria alternata in the root and petiole of Al (Mahobiya and Gupta 2017). However, as on date, only a few species of endophytic fungi are reported from the medicinal plant Al (TN, India). Hence, the current study based on 
endophytic fungi and its metabolites from leaves of a traditionally used medicinal plant Al will be of high value.

\section{Morphological Study}

Leaf samples of Al incubated on PDA and OA after surface sterilization showed rapid growth of fungi. Initially, growth of white cottony hyphae was observed at the inoculated site after 3 days in both PDA and OA (Fig. 1A \& 1B). After 7 days, the fungal isolate was sub cultured in fresh PDA and OA plates. Subcultured fungal isolates turned into smoky grey in color after 2 weeks and the fully differentiated mycelium showed fluffy texture. Fungal isolates showed black coloration on the reverse side with dense mycelial growth. On the other hand, the pod samples from the same Al plant, processed similarly as leaves, did not show growth of any isolate after 5 days (Fig S1). This indicates that the endophytic fungi might be localized to the plant leaves. Lack of fungal isolate from pods harvested from the same Al plant along with the leaves also served the secondary purpose of internal controls.

Light microscopic analysis of the fungi stained with Lactophenol and cotton blue clearly visualized the structural characteristics of the isolates. Fungal isolates from both the leaf samples showed similar morphological features. The hyphae were septate with thin and thick walls (Fig. 2A), while the conidiogenous cells were hyaline and cylindrical (Fig. 2B). Conidiophores were irregularly branched with conidiogenous cells originating from each ends (Fig. 2C). The septate conidiophores form dichotomous and trichotomous branches with clusters of conidia at the terminus (Fig. 2D). Thick walled hyphae of the fugal isolates showed brownish black exudates on its surface (Fig. 2E). Conidia were hyaline and ellipsoid with attenuated base with approximately 4.3-4.7 $\mu \mathrm{m}$ in length and 2.0-2.25 $\mu \mathrm{m}$ in diameter (Fig. 2F). These specific features indicate that the isolates belong to the family Hypoxylaceae and genus Daldinia. Both AI.EF 001 and AI.EF 002 fungal isolates shared similar morphological and structural characteristics indicating that they both belong to the same genus Daldinia.

\section{Molecular Study}

Identification of Al.EF001 and Al.EF002 at species level based on these morphological characteristics seemed difficult and could lead to ambiguity, hence PCR based ITS sequence analysis was carried out to further confirm the species of fungal isolates (Chan et al. 2019; $\mathrm{Ng}$ et al. 2016). DNA sequences from the isolates were subjected to molecular phylogenetic identification. ITS1-5.8-ITS2 sequences obtained from the fungal DNA were compared with the closely related sequences from GENBANK to reconstruct the phylogenetic tree. Ncbi-BLAST search of AI.EF001 and Al.EF002 DNA sequences identified them as DE. BLAST results also showed that the DNA sequence obtained from the isolates had several close matches.

Phylogenetic reconstruction for the isolates (Table 1) was done by neighbourhood joining $(\mathrm{NJ})$ method (kimura 2 parameter model for 1000 bootstrap replications) with reference isolates of DE and other closely related species of DE from BLAST which formed a cluster within DE group (Fig. 3). Hypoxylon fragiforme was used as outgroup. DNA sequences of both the fungal isolates shared a maximum identity 
of $100 \%$ with available data in NCBI and were grouped under the genera Daldinia. The isolates Al.EF 001 and Al.EF 002 showed high bootstrap values (100\%) with the DE strain FR852577 (Fig. 3), which

indicates the level of confidence within the clade. Hence, the phylogenetic analysis confirmed the isolates as DE. ITS sequences of Al.EF 001 and Al.EF 002 were submitted to GenBank with accession numbers MT712203 and MT712204 respectively 
Table 1

Details of Closely related isolates subjected to Phylogenetic Analysis

$\begin{array}{lllll}\text { FUNGAL } & \text { ISOLATE } & \text { GENBANK } & \text { PERCENTAGE } & \text { REFERENCES - NCBI } \\ \text { SPECIES } & & \text { ACCESSION NO } & \begin{array}{l}\text { IDENTITY } \\ \text { GENBANK }\end{array}\end{array}$

Daldinia

BPEF73

KF151849

$100 \%$

Sreeja et al. 2016

eschscholtzii

Daldinia

109_02_01b

MT507840

$100 \%$

Weerasinghe et al.

eschscholtzii

Daldinia $\quad$ KT 32

FR852577

$99.82 \%$

2020

eschscholtzii

Daldinia

JF 20

KT151578

$99.82 \%$

Jacob et al. 2015

eschscholtzii

Daldinia

RF 110

KT151596

$99.81 \%$

Ramya K.D et al. 2015

eschscholtzii

Daldinia

eschscholtzii

PB 65

MK333985

$99.81 \%$

Pan H et al. 2018

Daldinia

PB 66

MK333986

$99.81 \%$

Pan H et al. 2018

eschscholtzii

Daldinia

eschscholtzii

Daldinia

eschscholtzii

Daldinia

PB 77

MK333997

$99.81 \%$

Pan H et al. 2018

eschscholtzii

Daldinia

eschscholtzii

NQU283

MN368169

$99.81 \%$

Chan et al. 2019

Daldinia
eschscholtzii

Daldinia

eschscholtzii

KoRLI046086

MN341724

$99.81 \%$

Oh,S.-Y et al. 2019

Daldinia

eschscholtzii

115_02_02

MT507856

$99.81 \%$

Weerasinghe et al.

2020

$99.81 \%$

Weerasinghe et al.

2020

$99.81 \%$

Weerasinghe et al. 2020

Daldinia

theissenii

UZ_113_16 KY792621

MF380724

$99.81 \%$

Weerasinghe et al.

ALE 146

KU683758

$99.80 \%$

2020

CBS 113044

MW488225

$98.9 \%$

Yurnaliza $Y$ and

Daldinia
starbaecki

P14

KP012962

$98.8 \%$

Jamilh I 2021

Daldinia

MEL

caldariorum

2382610 
Earlier reports indicate that endophyte $\mathrm{DE}$, has been isolated from terrestrial plants, marine algae, mangroves, human nail scrapings, skin and blood (Stadler et al 2014; Helaly et al. 2018 ; Ng et al. 2016 ; Samarakoon S, 2019). Among plants, DE has also isolated from B.Sexangula var.rhynchopetala and leaves of Musa sp. (Yang et al. 2018; Samarakoon et al. 2019). Another strain of DE, A630 was isolated from the medicinal plant Pogostemon cablin (Liu et al. 2019). However, there is no known report of DE being isolated from any parts of the medicinal plant Al. This makes isolation of DE from Al leaves a potentially valuable finding.

\section{Phytochemical analysis of crude extracts}

Methanol extract of the isolated fungi Al.EF 001 \& Al.EF 002 were further fractionated using ethyl acetate and water. This yielded to mid polar fraction of Al.EF 001 and 002 (EFEA 001 and EFEA002). EFEA 001 and 002 were subjected to preliminary phytochemical analysis for the presence of flavonoids, tannins, steroids, saponins, Glycosides and terpenoids. EFEA001 confirmed the presence for all the tested phytochemicals except Tannins. EFEA 002 on the other hand showed the presence of only flavonoids, steroids, saponins, and terpenoids (Table 2). These family of phytochemical constituents identified in both the fungi are well known for their different types of bioactivity. It is of interest that both endophytic fungi showed a varying phytochemical profile in spite of sharing a common host.

Table 2

Phytochemical screeining of D.eschschcoltzii extract

\begin{tabular}{|lll|}
\hline COMPOUNDS & Al.EF 001 EA EXTRACT & Al.EF 002 EA EXTRACT \\
\hline Flavonoids & + & + \\
\hline Tannins & - & - \\
\hline Steroids & + & + \\
Saponins & + & + \\
Glycosides & + & - \\
\hline Terpenoids & + & + \\
\hline
\end{tabular}

\section{Assessment of Cell viability of EFEA against AtT 20 mouse pituitary cell lines}

Promising phytochemical results of EFEA 001 and 002 from the two DE isolates indicated the presence of molecules ranging from terpenes to flavanoids. These types of molecules are known to possess various therapeutic applications (Mishra et al. 2014). In line with this, toxicity of the crude EFEA fractions was investigated in this study.

Cytotoxic activity of EFEAon AtT 20 mouse pituitary cell lines was evaluated using FACS with the aid of $\mathrm{PI}$ staining. This type of PI based assay is a quick and reliable method to detect viable cells. PI experiment results showed significant concentration dependent cytotoxic activity for both the EFEA crude 
fractions. Upon treatment with EFEA 001, AtT 20 cells showed significant $(p<0.01)$ concentration dependent viability in the range of $50 \%-91 \%$ at concentrations of $0.15-2.5 \mathrm{mg} / \mathrm{ml}$ respectively. Similarly, EFEA 002 treatment showed $53 \%-83 \%$ cell viability at the tested concentrations (Fig. 4). At the highest tested concentration of $2.5 \mathrm{mg} / \mathrm{ml}$ both EFEA showed significantly $(p<0.01)$ least cytotoxicity compared to the positive control. The positive control, an anticancer drug Doxorubicin showed significantly higher cytotoxicity $(78 \%, p<0.01)$ against AtT 20 cells compared to both the fractions. These results show that the EFEA 001 possess significantly more viability against AtT 20 cell lines when compared to the EFEA 002. Hence, these results emphasize more towards the protective role of the extracts.

\section{Isolation and characterization of bioactive compounds from EFEA fractions}

In spite of several drugs being available for various diseases in the market, there is a constant search for drugs with better specificity and reduced side effects. This has turned the attention of researchers to molecules isolated from natural products. Promising bioactivity results of the current study indicates the presence of one or more bioactive metabolites in the DE fungal extract. Earlier attempts to characterize secondary metabolites from DE isolated from variety of sources, using HPLC and Sepadex LH resulted in identification of polar metabolites, BNTs, Cytochalasins, Daldinins and polyketides ( $\mathrm{Ng}$ et a.I 2016; Stadler et al. 2001; Tarman et al. 2012; Zhang et al. 2011). These phytochemicals have shown strong immunomodulatory effects (Helaly et al. 2018). In this study, the focus is on mid polar, EtOAc extract (partitioned using $\mathrm{H}_{2} \mathrm{O} /$ EtOAc). The EtOAc extract was subjected to silica gel column chromatography method using various combinations of Hexane and Ethylacetate, for separation of compounds identified using TLC. EFEA was subjected to column chromatography purification and compounds isolated by these means characterized using spectroscopic techniques.

EFEA 001 and EFEA 002 were subjected to further purification by silica gel-column chromatography. Column chromatographic separation of the EFEA 001 fraction yielded 7 major fractions, of which 5 fractions were identified as pure compounds (C1-C5). Similarly, the chromatographic separation of EFEA 002 fraction yielded 3 major compounds which were similar to compounds C1, C3 and C4 of EFEA 00. However, compounds C2 and C5 were absent or maybe present in undetectable amounts in EFEA 002. TLC analysis showed clear band with an $\mathrm{R}_{f}$ value of $0.9,0.75,0.7,0.5$ for compounds C1-C4 respectively and 0.3 for compound $C 5$ when eluted in chloroform:methanol: Acetic acid (9.4:0.3:0.3) solvent system. UV-VIS, FT-IR, Mass, ${ }^{1} \mathrm{H}$ and ${ }^{13} \mathrm{C}$ NMR spectral analysis were conducted for the isolated compounds $\mathrm{C} 1-\mathrm{C} 5$ (Fig S2 - S6) and used to elucidate the structure of the molecules. Further the obtained spectroscopic values (given below) were matched with the existing literature reports of the compounds and their structure confirmed (Fig. 5a-e) (Hwang et al. 2012 ; Brito-filho et al. 2017 ; Kaur et al. 2014 ; Yang et al. 2010 ; Haugrin et al. 2016)

\section{Compound 1 - $\square$ Napthoflavone (2-phenylbenzo chromen 4- one)}


Isolated as white amorphous powder. ${ }^{1} \mathrm{H}$ NMR $\left(\mathrm{CDCl}_{3}\right) \delta 8.61(1 \mathrm{H}, \mathrm{dt}) 8.18(1 \mathrm{H}, \mathrm{d}) 8.02(2 \mathrm{H}, \mathrm{dd}) 7.94(1 \mathrm{H}, \mathrm{d})$ $7.79(1 \mathrm{H}, \mathrm{d}) 7.72(2 \mathrm{H}, \mathrm{dd}) 7.58(3 \mathrm{H}, \mathrm{t}) 6.97(1 \mathrm{H}, \mathrm{s}) 7.69(1 \mathrm{H}, \mathrm{d})^{13} \mathrm{C}$ NMR $\left(\mathrm{CDCl}_{3}\right) 178.3(\mathrm{C}=0), 162.7,153.6$, 136.07, 132.02, 131.59, 129.29, 129.23, 128.29, 127.20, 126.29, 125.40, 124.18, 122.39, 120.80, 120.31, 129.31, 129.20, 108.88 FTIR (KBr, cm $\left.{ }^{-1}\right) 1609$ (C = 0), 1361, 1160, 1026, 660 UV $\lambda \max (\mathrm{MeOH}) \mathrm{nm}(\log \varepsilon$ ) $270, \mathrm{MS} \mathrm{m} / \mathrm{z}: 272\left(\mathrm{M}^{+}\right)$

\section{Compound 2 - Syringaldehyde (4-Hydroxy-3,5- dimethoxybenzaldehyde)}

Isolated as colourless crystals. ${ }^{1} \mathrm{H}$ NMR $\left(\mathrm{CDCl}_{3}\right) \delta 9.81(1 \mathrm{H}, \mathrm{s}) 7.15(2 \mathrm{H}, \mathrm{d}) 3.9(6 \mathrm{H}, \mathrm{s}){ }^{13} \mathrm{C} \mathrm{NMR}\left(\mathrm{CDCl}_{3}\right) 190$ $(\mathrm{C}=0), 56.2(\mathrm{O}-\mathrm{Me}), 128,106,147,140 \mathrm{FTIR}\left(\mathrm{KBr}, \mathrm{cm}^{-1}\right) 1670$ (C= 0), 1514, 1423, 1172, 1038 UV $\lambda$ max $(\mathrm{MeOH}) \mathrm{nm}(\log \varepsilon) 300, \mathrm{MS} \mathrm{m} / \mathrm{z}: 182\left(\mathrm{M}^{+}\right)$

\section{Compound 3-3,4,5 trimethoxy benzoic acid (Gallic acid trimethyl ether)}

Isolated as colourless crystals. ${ }^{1} \mathrm{H}$ NMR $\left.\left(\mathrm{CDCl}_{3}\right) \delta 7.28(2 \mathrm{H}, \mathrm{d}) 3.93(3 \mathrm{H}, \mathrm{s}) 3.81(6 \mathrm{H}, \mathrm{s}){ }^{13} \mathrm{C} \mathrm{NMR} \mathrm{CDCl}_{3}\right)$ 179 (C = 0), 56.2(O-Me), 60.9 (O-Me), 124.1,107.4, 152.9, 142.9 FTIR $\left(\mathrm{KBr} \mathrm{cm}^{-1}\right) 1686$ (C = 0), 3400, 3022, 1620, 1519, 1320, 2950, 2840 UV $\lambda \max (\mathrm{MeOH}) \mathrm{nm}(\log \varepsilon)$ 260, MS m/z: 201(M+)

\section{Compound 4 - 2 Furoic acid (Furan 2 carboxylic acid)}

Isolated as white crystalline solid. ${ }^{1} \mathrm{H}$ NMR (D6-DMSO) $\delta 7.9(1 \mathrm{H}, \mathrm{d}) 7.22(1 \mathrm{H}, \mathrm{dd}) 6.65(1 \mathrm{H}, \mathrm{dd}){ }^{13} \mathrm{C}$ NMR (D6-DMSO) 159.8,147.4, 145.3, 118.2, 112.5 FTIR (KBr cm $\left.{ }^{-1}\right) 3150,1715,1694$ UV $\lambda \max (\mathrm{MeOH}) \mathrm{nm}(\log$ ع ) $265, \mathrm{MS} \mathrm{m} / \mathrm{z:} 112.08\left(\mathrm{M}^{+}\right)$

Compound 5- Gossypetin3' 0 glycoside (2-(3,4-dihydroxyphenyl)-5,7,8-trihydroxy-3-[(2 S,5S,6R)-3,4,5trihydroxy-6(hydroxymethyl)oxan-2-yl]oxychromen-4-one)

Isolated as yellow amorphous powder. ${ }^{1} \mathrm{H}$ NMR (D6-DMSO) $\delta 12.34(1 \mathrm{H}, \mathrm{s}) 9.65(1 \mathrm{H}, \mathrm{s}) 9.46(1 \mathrm{H}, \mathrm{s}) 9.31$ $(1 \mathrm{H}, \mathrm{s}) 7.88(1 \mathrm{H}, \mathrm{d}) 7.81(1 \mathrm{H}, \mathrm{dd}) 6.91(1 \mathrm{H}, \mathrm{d}) 6.26(1 \mathrm{H}, \mathrm{s}) 5.32(1 \mathrm{H}, \mathrm{d}) 5.08(1 \mathrm{H}, \mathrm{d}) 4.84(1 \mathrm{H}, \mathrm{d}) 4.66(1 \mathrm{H}, \mathrm{d})$ $3.42(2 \mathrm{H}, \mathrm{t}) 3.32(3 \mathrm{H}, \mathrm{dd}) 3.24(1 \mathrm{H}, \mathrm{s})^{13} \mathrm{C}$ NMR (D6-DMSO) 176.5, 157.07, 157.02, 149.02, 148.49, 147.9, 145.5, 136.4, 125.7, 122.7, 121.6, 116.3, 116.1, 106.9, 103.6, 99, 77.7, 76.6, 74.7, 69.81, 61.1. FTIR $(\mathrm{KBr}$ $\left.\mathrm{cm}^{-1}\right)$ 1597, $1657(\mathrm{C}=0), 3175(-\mathrm{OH})$ UV $\lambda \max (\mathrm{MeOH}) \mathrm{nm}(\log \varepsilon) 380, \mathrm{MS} \mathrm{m} / \mathrm{z}: 480\left(\mathrm{M}^{+}\right)$

Based on the spectroscopic data and literature reports, C1 was identified as $₫$ Napthoflavone, C2 as Syringaldehyde, C3 as 3,4,5-trimethoxy benzoic acid, C4 as 2-Furoic acid and C5 as Gossypetin-3'-0glycoside. Comprehensive survey of earlier literature reports indicates that, so far there have been no known reports of these 5 compounds being isolated and characterized from either Al or DE. Hence, the current study is a first-time report of all these 5 compounds in DE. However, C1, C2 and C4 have been reported earlier in other plant species as well as endophytic fungi (Brito-filho et al. 2010 ; Haugrin et al. 2016 ; Yang et al. 2010). Similarly C3 has already been reported in another Daldinia sp. (Liarzi et al. 2016) 
but not in DE. Compound C5 on the other hand as so far been identified and reported only from one plant Talipariti elatum S(Haugrin et al. 2016) making this finding a very valuable alternative source for gossypetin-3'-0-glycoside. Notably, syringic acid and gossypetin-8-0-glycoside have already been reported in Al. This raises the possibility that, these two compounds could have been derived from $\mathrm{C} 2$ and $\mathrm{C} 5$ respectively by oxidation and isomerization, indicating a viable biosynthetic link between $\mathrm{Al}$ and $\mathrm{DE}$. However, detailed investigation is needed before confirming the biosynthetic link between Al and DE. Also, the compounds syringaldehyde and Gossypetin 3'O glycoside are absent in the fraction EFEA 002. This could be the basis for difference in bioactivity of EFEA 001 compared to EFEA 002. Overall, the identification of DE from the plant Al serves as a valuable source for the production of several of these compounds, especially the flavone derivatives like gossypetin.

\section{Quantification of isolated compounds}

The 5 phytoconstituents isolated for the first time from the endophytic fungi DE were quantified using HPTLC. HPTLC validation and quantification of phytoconstituents has become an effective and valuable tool (Noman et al. 2020). Ease of use, as well as the flexibility of using multiple solvent systems, makes it an ideal tool for quantifying several constituents simultaneously in the EFEA. Linearity for each compound was obtained by plotting different concentrations $(7.5-1000 \mu \mathrm{g} / \mathrm{ml})$ against their respective

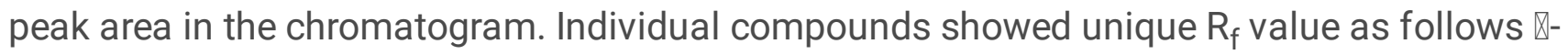

napthoflavone (0.93), syringaldehyde (0.70), 3,4,5 trimethoxy benzoic acid (0.68), 2-Furoic acid (0.39) and Gossypetin 3' O glycoside (0.90) (Fig S7 \& S8). $R_{f}$ values of the compounds were used to match with EFEA and peak areas used to quantify the amount of compound present in the extract (Table S1). Regression equations and correlation co-efficients for the individual compounds obtained from the linearity plot were used for accurately calculating the amount of compounds present in EFEA (Fig. 6). The

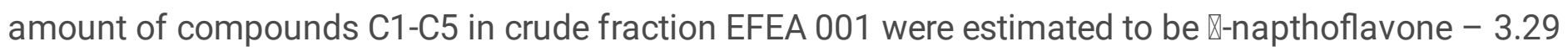
$\mathrm{mg}$, Syringaldehyde $-2.24 \mathrm{mg}, 3,4,5$ trimethoxy benzoic acid $-4.8 \mathrm{mg}, 2$-Furoic acid $-6.4 \mathrm{mg}$ and Gossypetin 3' 0 glycoside $-4.6 \mathrm{mg}$ of dried weight of $30 \mathrm{mg}$ of crude fraction respectively whereas the amount of compounds $\mathrm{C} 1, \mathrm{C} 3$ and $\mathrm{C} 4$ in crude fraction EFEA 002 were estimated as $1.2 \mathrm{mg}, 1.6 \mathrm{mg}$ and $2.1 \mathrm{mg}$ respectively. These results indicate that although the compounds present in EFEA 002 were

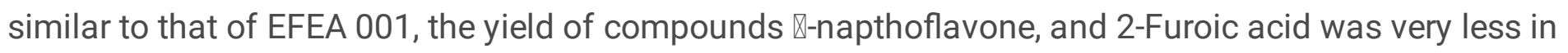
EFEA 002 when compared to EFEA 001.

\section{Determination of cell viability and $\mathrm{IC}_{50}$ concentrations of the isolated compounds}

Earlier cytotoxic assays showed least cytotoxic activity for EFEA. It would be of interest to see if any or all of the 5 compounds isolated from EFEA share this activity. Compounds $\mathrm{C} 1-\mathrm{C} 5$ at a concentration range of $0.03 \mathrm{mg}-1 \mathrm{mg} / \mathrm{ml}$ was used to assess the cytotoxicity in AtT 20 cells using MTT assay. All the 5 compounds showed significant viability ranging from $42 \%-85 \%, 61 \%-92 \%, 42 \%-89 \%, 49 \%-81 \%$ and $64 \%-95 \%$ respectively in AtT 20 cells (Fig. 7). Some of the findings were in line with existing literature reports, which indicate that syringaldehyde exerts neuroprotective effect through anti-oxidant and anti- 
apoptotic activities (Bozkurt et al. 2014). Similarly, Gossypetin 3'O glycoside has also been reported to exhibit strong anti oxidant activity (Haugrin et al. 2016). These findings suggest that compounds isolated from the Al leaf endophytic fungus DE could be valuable source for bioactive compounds.

Also, from these studies the $\mathrm{IC}_{50}$ values of all the compounds were determined as $\mathrm{C} 1-0.1, \mathrm{C} 2-0.15, \mathrm{C} 3-$ 0.15 , C4 -0.125 and $\mathrm{C} 5-0.1 \mathrm{mg} / \mathrm{ml}$. These $\mathrm{IC}_{50}$ concentrations were used for further in vitro assays.

\section{Antioxidant activities of the isolated compounds}

To evaluate the antioxidant ability of the isolated compounds to scavenge the free radicals DPPH, ABTS, Superoxide anions and hydroxyl ions radical scavenging assays were carried out. Ascorbic acid was used as positive control for all the assays.

DPPH is a stable, nitrogen centered free radical which upon reduction changes from violet to yellow colour. The change in the colour depends upon the scavenging abilities of antioxidant extracts or pure compounds as it reduces the DPPH radical by donating hydrogen (Batool et al. 2019). All the compounds isolated showed strong radical scavenging activities. Compound $\mathrm{C} 1$ showed scavenging activities at a range of $41 \%-74 \%$, compound C2 31\% -68\%, compound C3-50\%-81\%, compound C4 $42 \%-76 \%$ and compound C5 51\% - 86\% (Fig. 8a). The compounds showed significant $(p<0.01)$ concentration dependent antioxidant activities, the higher concentration exhibited highest radical scavenging activity. This was on par with the positive control ascorbic acid which possessed $61 \%-94 \%$ antioxidant activity.

ABTS radical is both lipid soluble and water soluble radical which is used to evaluate the antioxidant status of compounds or extracts (Saanasimuthu et al. 2018). In this study, the compounds C1-C5 strongly scavenged ABTS free radical at all tested concentrations. The compounds showed significant ( $\mathrm{p}$ $<0.01$ ) concentration dependent antioxidant activity with C1 27\% - 71\%, C2 21\%-63\%, C3 25\%-58\%, C4 $38 \%-71 \%$ and C5 $43 \%-83 \%$ radical scavenging activities (Fig. 8b). The positive control ascorbic acid exhibited $61 \%-92 \%$ ABTS scavenging activity.

Superoxide anion is one of the crucial free radicals which are formed by the addition of an electron to molecular oxygen. Superoxide radical easily reacts with nucleic acids, amino acids, lipids in the cell membrane to exert a robust toxic effect (Luo et al. 2019). Hence, it is very essential to study the efficacy of a compound to scavenge superoxide radical. Our results showed concentration dependent scavenging activity of superoxide radicals at all tested concentrations. The compound C1 showed $28 \%-69 \%$ scavenging activity, C2 showed $40 \%-75 \%$, C3 showed $31 \%-64 \%$, C4 showed $39 \%-79 \%$, C5 possessed $51 \%-83 \%(p<0.01)$ scavenging activities (Fig. $8 c)$. This was similar to that of the scavenging activities of ascorbic acid $(61 \%-91 \%)$.

Hydroxyl radical is a potent reactive species which cause severe pathogenesis to cell membrane phospholipids and react with polyunsaturated fatty acids. It is very short lived toxic free radicals which cause severe damage to cellular integrity (Batool et al. 2019). Therefore compounds that exhibit antioxidant against the hydroxyl radicals are needed for balancing the redox state in the cells and to 
deactivate the radical. In this study, the compounds C1-C5 showed strong scavenging potential against hydroxyl radicals. Compound $\mathrm{C} 1$ showed $28 \%-69 \%$ scavenging activity at concentrations $0.06-1$ $\mathrm{mg} / \mathrm{ml}$. Compound C2 showed 40\% - 75\%, C3 31\% -64\%, C4 39\% - 79\% and C5 showed $51 \%-83 \%$ ( $\mathrm{p}<$ 0.01 ) hydroxyl ions scavenging activity (Fig. 8d). Ascorbic acid showed 64\% - 91\% activity.

These assays show that the compounds isolated from D.eschscholtzii possess strong antioxidant activity. Antioxidants are crucial substances which possess the ability to protect the body from damage caused by free radical induced oxidative stress. Our study showed that all the isolated compounds possess the ability to trap and scavenge the free radicals and thus it can inhibit the oxidative stress that lead to several degenerative diseases.

\section{Intracellular free radical scavenging activity in AtT 20 mouse pituitary cell lines}

To understand the influence of isolated compounds on intracellular oxidative stress, DCFDA stained AtT 20 cells were used for FACS analysis. The non fluorescent DCFH-DA dye that easily penetrates into the cells gets hydrolyzed by intracellular esterase to become DCFH, and this compound is trapped inside the cells further gets oxidized by peroxide (Sannasimuthu A et al. 2019). FACS analysis revealed that the compounds $\mathrm{C} 1-\mathrm{C} 5$ at their $\mathrm{IC}_{50}$ concentrations significantly reduced the extent of free radical generation. AtT 20 cells when treated with compounds $\mathrm{C} 1-\mathrm{C} 5$ along with peroxide $(50 \mu \mathrm{m})$ showed a significant $(\mathrm{p}<$ $0.001)$ reduction in the fluorescence intensity when compared to cells treated with peroxide alone (94\%). Compound C1 exhibited 35\%, C2 31\%, C3 29\%, C4 38\% and C5 15\% ROS generation (Fig. 9a\&b).

Among the 5 compounds, $\mathrm{C} 5$ exhibited most promising intracellular radical scavenging activity (approx $80 \%$ ). These results confirmed that the isolated compounds exhibited the potential to reduce the intracellular oxidative stress in AtT 20 cells. Earlier work in our lab has shown that inhibition of ROS generation in cells activated by peroxide plays a crucial role in down regulating the cellular inflammatory process (V.Cheeran and G.Munuswamy-Ramanujam 2020). Hence the ability of the compounds to scavenge the intracellular ROS serves as an indicator for identifying potential anti-inflammatory activity of the isolated compounds.

\section{In vitro nitric oxide inhibitory activity of isolated compounds in AtT 20 cells}

Nitric oxide (NO) is an intracellular mediator produced by inducible Nitric oxide synthase (iNOS) in various mammalian cells. NO is known to be responsible for the vasodilation and hypotension observed in septic shock and inflammation. However, overproduction of NO could result in tissue damage and activation of proinflammatory mediators associated with acute and chronic inflammation (Dzoyem JP et al. 2016). In the present study, the NO scavenging capacity of the compounds was determined by decrease in the absorbance at $550 \mathrm{~nm}$, as a result of reduction of NO production. The inhibitory activity of NO was demonstrated in all the compounds $\mathrm{C} 1-\mathrm{C} 5$ at their $\mathrm{IC}_{50}$ concentrations in AtT 20 mouse pituitary cells. The cells when treated with compounds C1-C5 along with LPS showed a significant $(p<0.01)$ decrease in 
the generation of NO when compared to the LPS induced cells (92\% NO generation). The compounds C1C5 showed 32\%, 39\%, 36\%, 41\% and 22\% NO generation respectively (Fig. 10). Once again the best inhibitory activity against NO was seen in compound $\mathrm{C} 5$. These results were in line with our previous results supporting the antioxidant and anti-inflammatory activity of the isolated compounds. Hence, the anti-inflammatory activity of these compounds isolated from DE targeting NO inhibition might serve as potential candidates for the treatment of inflammatory diseases caused due to the overproduction of Nitric oxide.

\section{In vitro lipid peroxidation activity of isolated compounds in AtT 20 mouse pituitary cells}

Lipid peroxidation is a essential marker of oxidative stress induced inflammation. LPS induced generation of free radicals is well known promoters of lipid peroxidation, the severity of which can be assessed by the measurement of malondialdehyde (MDA). Overproduction of free radicals causes an increase in the levels of malondialdehyde which is commonly known as a marker of oxidative stress (Hazandazeh et al, 2017). In the present study, concentration of MDA as a marker of lipid peroxidation was determined using Thiobarbituric acid reactive substances (TBARS) assay in AtT 20 mouse pituitary cells. The compounds C1-C5 significantly $(p<0.01)$ inhibited lipid peroxidation at their $\mathrm{IC}_{50}$ concentrations in AtT 20 cells. The pink coloured MDA-TBA abduct formed significantly decreased upon treatment with compounds C1-C5 (5.9, 5.1, 4.1, 6, $3.5 \mathrm{nmol} / \mathrm{g} \mathrm{MDA})$ when compared to the LPS induced cells (12 nmol/g) (Fig. 11). This decrease in the MDA levels indicates that the compounds C1-C5 are effective inhibitors of lipid peroxidation in AtT 20 cells and this potential reveals the efficacy of compounds as anti-inflammatory agents.

\section{Conclusion}

In the present investigation, we report for the first time isolation of an endophytic fungus, D. eschscholtzii from the leaves of medicinal plant Al. The endophyte was localized to the leaf of Al. Further chromatographic and spectroscopic analysis carried out to identify secondary metabolites revealed the

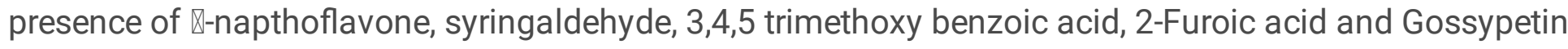
3' O glycoside. All of these compounds are being reported for the first time in DE. Presence of Gossypetin $3^{\prime} \mathrm{O}$ glycoside in DE is unique since so far only one study has reported the presence of the compound in a plant Talipariti elatum S. Further the study reports in vitro anti-oxidant and anti-inflammatory activities of isolated compounds. Ability exhibited by the compounds to downregulate oxidant levels and lipid peroxidation in mouse pituitary cell lines, indicate the ability of isolated phyto compounds to modulate the neural inflammation. Overall the current study clearly demonstrates the medicinal value of the endophytic fungus D.eschscholtzii in providing valuable phytochemicals, including flavones with possible novel bioactive applications.

\section{Abbreviations}


Al Abutilon indicum, DE Daldinia eschscholtzii, EA ethyl acetate, NJ Neighbour joining method, MTT 3-(4,5 dimethylthiazol-2-yl)-5-diphenyl tetrazolium bromide, NCCS National Centre for Cell Sciences, DMEM Dulbecco's modified Eagles medium, BS Bacillus subtilis, KP Klebsiella pneumonia, PCR Polymerase chain reaction, PBS Phosphate buffered saline, FBS Fetal bovine serum, DMSO Dimethyl sulfoxide, PI Propidium iodide, FACS Fluorescence activated cell sorting.

\section{Declarations}

\section{Funding}

Dr. Ganesh Munuswamy-Ramanujam acknowledges Department of Biotechnology (DBT) India for supporting this research work (BT/PR9930/NDB/39/457/2013).

\section{Conflicts Of Interest}

The authors declare no conflict of interest.

\section{Availability of data and material}

The datasets generated during and/or analyzed during the current study are available from the corresponding author on reasonable request.

Sequence data is deposited in the public repository NCBI-GENBANK and accession numbers are included in the manuscript

\section{Code availability}

Not applicable

\section{Author Contributions}

Dr. Ganesh Munuswamy-Ramanujam - Designed the study, Analyzed the data, Supervision, Shazia Anjum Musthafa - Performed research, wrote the paper, Analyzed the data, Kesavan Muthu, Muhammad Sadiq, Saraniya Sekar - Performed research, Dhamodaran Umapathy - Analyzed the data

\section{References}

Adebayo, S. A., Ondua, M., Shai, L. J., \&Lebelo, S. L. (2019) Inhibition of nitric oxide production and free radical scavenging activities of four South African medicinal plants. Journal of inflammation research, 12, 195-203. https://doi.org/10.2147/JIR.S199377

Anbazahan Sannasimuthu, Venkatesh Kumaresan, Shreya Anilkumar, Mukesh Pasupuleti, MunuswamyRamanujam Ganesh, Kanchana Mala, Bilal Ahmad Paray, Mohammad K. Al-Sadoon, Mohammed Fahad Albeshr, Jesu Arockiaraj (2019) Design and characterization of a novel Arthrospira platensis glutathione 
oxido-reductase-derived antioxidant peptide GM15 and its potent anticancer activity via caspase-9 mediated apoptosis in oral cancer cells. Free radical biology and medicine 198-209. https://doi.org/10.1016/j.freeradbiomed.2019.03.006

Archna Sharma, R.A. Sharma, Hemlata Singh (2013) Phytochemical and Pharmacological Profile of Abutilon Indicum L. Sweet : A Review, Int. J. Pharm. Sci. Rev. Res., 20(1).

Batool, R., Khan, M.R., Sajid, M. et al (2019) Estimation of phytochemical constituents and in vitro antioxidant potencies of Brachychiton populneus (Schott \& Endl.) R.Br . BMC Chemistry 13, 32 .https://doi.org/10.1186/s13065-019-0549-z

Bonito,G., Barrett,M., Udovicic, F. and Lebel,T (2014). Fleshy Macrofungi of Northern Tropical Australia: Filling in the sampling gap. NCBI GENBANK

Bozkurt, A. A., Mustafa, G., Tarık, A., Adile, O., Murat, S. H., Mesut, K., Yıldıray, K., Coskun, S., \& Murat, C (2014) Syringaldehyde exerts neuroprotective effect on cerebral ischemia injury in rats through antioxidative and anti-apoptotic properties. Neural regeneration research, 9 (21), 1884-1890. https://doi.org/10.4103/1673-5374.145353

C.F. Chi, B. Wang, Y.M. Wang, S.G. Deng, J.Y. Ma (2014) Isolation and characterization of three antioxidant pentapeptides from protein hydrolysate of monkfish (Lophius litulon) muscle, Food Res. Int. 55 , 222-228. https://doi.org/10.1016/j.foodres.2013.11.018

Chan CL, Yew SM, Ngeow YF, Na SL, Lee KW, Hoh CC, Yee WY, Ng KP (2015) Genome analysis of Daldiniaeschscholtzii strains UM 1400 and UM 1020, wood-decaying fungi isolated from human hosts. BMC Genomics 16:966 DOI 10.1186/s12864-015-2200-2

Chan,C.F. and Chi,W.C (2019) Seasonal variation, antibacterial activity of endophytic fungi associated with Zanthoxylum simulans Hance at Kinmen. NCBI GENBANK

Chatterjee S, Ghosh R, Mandal NC (2019) Production of bioactive compounds with bactericidal and antioxidant potential by endophytic fungus Alternaria alternata AE1 isolated from Azadirachta indica A. Juss. PLoS ONE 14(4): e0214744. http://sci-hub.tw/10.1371/journal.pone.0214744

Cheeran, V., \& Munuswamy-Ramanujam, G (2020) Sesquiterpene lactone Zaluzanin D alters MMP-9 promoter methylation in differentiated THP-1 monocytic cells and down regulates inflammatory cytokines IL-1 $\beta$ and TNF-a. International immunopharmacology, 87,106803. https://doi.org/10.1016/j.intimp.2020.106803

Deepika Mahobiya and Ashwini Kumar Gupta (2017) Diversity of endophytic fungi associated with some medicinal herbs and shrubs. KAVAKA 49: 38-44.

Dzoyem, J. P., Donfack, A. R., Tane, P., McGaw, L. J., \& Eloff, J. N (2016) Inhibition of Nitric Oxide Production in LPS-Stimulated RAW 264.7 Macrophages and 15-LOX Activity by Anthraquinones from 
Pentasschimperi. Planta medica, 82 (14), 1246-1251. https://doi.org/10.1055/s-0042-104417

Ejikeme, C., Ezeonu, C. S., \& Eboatu, A. N. (2014) Determination of Physical and Phytochemical Constituents of some Tropical Timbers Indigenous to nigerdelta area of nigeria. European Scientific Journal, 10(18), 247-270. https://doi.org/10.19044/esj.2014.

Eugene chang, Choon Young Kim (2018) Lipid peroxidation and antioxidant activities of the aqueous Rhizome extract of Rheum Officinale Baillon. Journal of food quality, vol 2018. https://doi.org/10.1155/2018/5258276

Fouda, A. H., Hassan, S. E. D., Eid, A. M., \&Ewais, E. E. D (2015) Biotechnological applications of fungal endophytes associated with medicinal plant Asclepiassinaica (Bioss.). Annals of Agricultural Sciences, 60(1), 95-104.https://doi.org/10.1016/j.aoas.2015.04.001

François-Haugrin, F., Monan, M., Nossin, E., Smith-ravin, J., \& Marcelin, O (2016) Antioxidant activity of an isomer of gossypitrin (gossypetin-3'-0-glucoside) isolated in the petals of Talipariti elatum Sw., and determination of total phenolic content of the total flower. Journal of Pharmacognosy and Phytochemistry, 5, 200-208.

Gupta, D., Mandal, R.,Puttey, J. S., \& Sandhu, S. S (2014) Screening of endophytic fungi isolated from some medicinal plants in Jabalpur region for antibacterial activity. World Journal of Pharmacy and Pharmaceutical Sciences, 3(7), 1655-1666.

Hasanzadeh, D., Mahdavi, M., Dehghan, G., \&Charoudeh, H. N (2017) Farnesiferol C induces cell cycle arrest and apoptosis mediated by oxidative stress in MCF-7 cell line. Toxicology reports. 4, 420-426. https://doi.org/10.1016/j.toxrep.2017.07.010

Helaly, S. E., Thongbai, B., \& Stadler, M (2018) Diversity of biologically active secondary metabolites from endophytic and saprotrophic fungi of the ascomycete order Xylariales. Natural product reports, 35(9), 992-1014. https://doi.org/10.1039/c8np00010g

Hong-Xin Liu, Hai-Bo Tan, Sai-Ni Li, Yu-Chan Chen, Hao-Hua Li \& Wei-Min Zhang (2019) Two new metabolites from Daldinia eschscholtzii, an endophytic fungus derived from Pogostemon cablin, Journal of Asian Natural Products Research, 21:2, 150-156. https://doi.org/10.1080/10286020.2017.1392512

Hussain, T., Tan, B., Yin, Y., Blachier, F., Tossou, M. C., \& Rahu, N (2016) Oxidative Stress and Inflammation: What Polyphenols Can Do for Us?. Oxidative medicine and cellular longevity. 7432797. https://doi.org/10.1155/2016/7432797

Hwang, D., Jo, G., Hyun, J., Lee, S.D., Koh, D., \& Lim, Y (2012) Synthesis of methoxybenzoflavones and assignments of their NMR data. Magnetic Resonance in Chemistry. 50.DOI: 10.1002/mrc.3790

Jacob,J.C., Ramya,K.D. and Philip,R (2015) Microbial diversity in the continental shelf sediments of south east coast of India. NCBI GENBANK 
Jia, M., Chen, L., Xin, H. L., Zheng, C. J., Rahman, K., Han, T., \& Qin, L. P (2016) A Friendly Relationship between Endophytic Fungi and Medicinal Plants: A Systematic Review. Frontiers in microbiology, 7, 906. https://doi.org/10.3389/fmicb.2016.00906

Kuan CS, Yew SM, Toh YF, Chan CL, Lim SK, Lee KW, Na SL, Hoh CC, Yee WY, Ng KP (2015) Identification and characterization of a rare fungus, Quambalaria cyanescens, isolated from the peritoneal fluid of a patient after nocturnal intermittent peritoneal dialysis. PLoS ONE. 2015;10:e0145932. doi: 10.1371/journal.pone.0145932.

Kustiariyah Tarman, Gottfried J. Palm, Andrea Porzel, Kurt Merzweiler, Norbert Arnold, Ludger A. Wessjohann, Martin Unterseher, Ulrike Lindequist (2012) Helicascolide C, a new lactone from an Indonesian marine algicolous strain of Daldinia eschscholzii (Xylariaceae, Ascomycota) Phytochemistry Letters : 83-86

1. Li, H. Pan, Y. F. Liu, D. W. Li, Q. Zhang, L. Deng, M. Y. Chen, C. H. Zhong, (2018) First Report of Nigrospora sphaerica causing Kiwifruit Postharvest Rot Disease in China, Plant Disease, 10.1094/PDIS-12-17-1886-PDN,102, 8, (1666).

Liarzi, O., Bar, E., Lewinsohn, E., \& Ezra, D (2016) Use of the Endophytic Fungus Daldinia cf. concentrica and Its Volatiles as Bio-Control Agents. PloS one, 17(12), e0168242.

https://doi.org/10.1371/journal.pone.0168242

Lu-Jia Yang, Hai-Xia Liao, Meng Bai, Guo-Lei Huang, You-Ping Luo, Yan-Yan Niu, Cai-Juan Zheng \& Chang-Yun Wang (2018) One new cytochalasin metabolite isolated from a mangrove-derived fungus Daldinia eschscholtzii HJ001, Natural Product Research, 32:2, 208-

213, https://doi.org/10.1080/14786419.2017.1346641

Luo, S., Jiang, X., Jia, L., Tan, C., Li, M., Yang, Q., Du, Y., \& Ding, C. (2019). In Vivo and In Vitro Antioxidant Activities of Methanol Extracts from Olive Leaves on Caenorhabditis elegans. Molecules (Basel, Switzerland), 24(4), 704. https://doi.org/10.3390/molecules24040704

Mishra, Y., Singh, A., Batra, A., \& Sharma, M. M (2014) Understanding the biodiversity and biological applications of endophytic fungi: a review. J. Microbiol. Biochem. Technol. S, 8. Doi: 10.4172/19485948.S8-004

Ng, K. P., Chan, C. L., Yew, S. M., Yeo, S. K., Toh, Y. F., Looi, H. K., Na, S. L., Lee, K. W., Yee, W. Y., \&Kuan, C. S (2016) Identification and characterization of Daldiniaeschscholtzii isolated from skin scrapings, nails, and blood. PeerJ, 4, e2637.https://doi.org/10.7717/peerj.2637

Noman, O.M., Nasr, F.A., Mothana, R., Alqahtani, A.S., Qamar, W., Al-Mishari, A.A., Al-Rehaily, A., Siddiqui, N., Alam, P., \&Almarfadi, O.M (2020) Isolation, Characterization, and HPTLC-Quantification of Compounds with Anticancer Potential from Loranthus Acaciae Zucc. Separations, 7, 43.https://doi.org/10.3390/separations7030043 
Oh, S.-Y.; Yang, J.H.; Woo, J.-J.; Oh, S.-O.; Hur, J.-S (2020) Diversity and Distribution Patterns of Endolichenic Fungi in Jeju Island, South Korea. Sustainability, 12, 3769.

Padhi, L.,Mohanta, Y. K., \& Panda, S. K (2013) Endophytic fungi with great promises: A Review. Journal of Advanced Pharmacy Education \& Research, 3(3).

Pedra, N. S., Galdino, K., da Silva, D. S., Ramos, P. T., Bona, N. P., Soares, M., Azambuja, J. H., Canuto, K. M., de Brito, E. S., Ribeiro, P., Souza, A., Cunico, W., Stefanello, F. M., Spanevello, R. M., \&Braganhol, E (2018) Endophytic Fungus Isolated From Achyrocline satureioides Exhibits Selective Antiglioma Activity-TheRole of Sch-642305. Frontiers in oncology, 8, 476.https://doi.org/10.3389/fonc.2018.00476

Rahman Gul., Syed umar Jan., Syed Faridullah., Samiullah Sherani., Nusrat Jahan (2017) Preliminary phytochemical screening, quantitative analysis of alkaloids and anti-oxidant activity of crude plant extracts from Ephedra intermedia indigenous to Balochistan. The scientific world journal. https://doi.org/10.1155/2017/5873648

Ramachandran, S., Loganathan, S., Cheeran, V., Charles, S., Munuswamy-Ramanujan, G., Ramasamy, M., Raj, V., \& Mala, K (2018) Forskolin attenuates doxorubicin-induced accumulation of asymmetric dimethylarginine and s-adenosylhomocysteine via methyltransferase activity in leukemic monocytes. Leukemia research reports, 9, 28-35.https://doi.org/10.1016/j.Irr.2018.02.001

Ramninder kaur, Komalpreet kaur, Lalit gupta, Nisha dhir, Gaganpreet (2014) Synthesis and Biological evaluation of Gallic acid peptide Derivatives. Int. J. Pharm. Sci. Rev. Res., 28(1), P 16-21. DOI: 10.32553/jbpr.v8i3.631

Ramya,K.D., Jacob,J.C. and Philip,R. (2015) Microflora in the continental shelf sediments of south west coast of India. NCBI GENBANK

Saeed Mollaei, Omid Khanehbarndaz, Zahra Gerami-Khashal, Mostafa Ebadi. (2019) Molecular identification and phytochemical screening of endophytic fungi isolated from Lithospermum officinale $L$ roots: A new source of Shikonin. Phytochemistry 168, 112116.

https://doi.org/10.1016/j.phytochem.2019.112116

Samarakoon, S. (2019) The first report of Daldiniaeschscholtzii as an endophyte from leaves of Musa sp. (Musaceae) in Thailand. Asian Journal of Mycology 2(1): 183-197. Doi 10.5943/ajom/2/1/9.

Sannasimuthu A, V. Kumaresan, M. Pasupuleti, B.A. Paray, M.K. Al-Sadoon, J. Arockiaraj, (2018) Radical scavenging property of a novel peptide derived from Cterminal domain of superoxide dismutase enzyme in Arthrospira platensis, Algal Res 35 519-529. https://doi.org/10.1016/j.algal.2018.09.028

Seetharaman, P., Gnanasekar, S., Chandrasekaran, R. Chandrakasan G., Kadarkarai M., Sivaperumal S (2017) Isolation and characterization of anticancer flavone chrysin (5,7-dihydroxy flavone)-producing 
endophytic fungi from Passiflora incarnata L. leaves. Ann Microbiol 67, 321-331. https://doi.org/10.1007/s13213-017-1263-5

Severino Gonçalves de Brito-Filho, Jéssica Karina da Silva Maciel, Yanna Carolina Ferreira Teles, Milen Maria Magalhães de Souza Fernandes, Otemberg Souza Chaves et al., (2017) Phytochemical study of Pilosocereuspachycladus and antibiotic-resistance modifying activity of syringaldehyde. Revista Brasileira de Farmacognosia, Volume 27, Issue 4, Pages 453-458.

https://doi.org/10.1016/j.bjp.2017.06.001

Shazia Anjum Musthafa, Thilakavathi Kasinathan, Ritobrata Bhattacharyya, Kesavan Muthu, Sathish Kumar, Ganesh Munuswamy-Ramanujam. (2020) Gallic acid synergistically enhances the apoptotic ability of Abutilon indicum Linn. Stem fraction inhuman U87 glioblastoma cells, Materials Today: Proceedings. https://doi.org/10.1016/j.matpr.2020.10.285

Sreeja, K., Anandaraj, M., \&Bhai, R. S (2016) In vitro evaluation of fungal endophytes of black pepper against Phytophthora capsici and Radopholussimilis. Journal of Spices and Aromatic Crops, 25(2), 113122.

Stadler, M., Læssøe, T., Fournier, J., Decock, C., Schmieschek, B., Tichy, H. V., \&Peršoh, D. (2014) A polyphasic taxonomy of Daldinia (Xylariaceae).Studies in mycology, 77(1), 1-143. https://doi.org/10.3114/sim0016

Suryanarayanan, T.S., Senthilarasu, G., \&Muruganandam, V. (2007) Endophytic fungi from Cuscutareflexa and its host plants, Fungal diversity, 4:117-123.

Suryawanshi V.S. \& S.R. Umate. (2020) A review on Phytochemical constituents of Abutilon indicum (Link) Sweet - An important medicinal plant in Ayurveda., Pla. Sci. 2020; Vol. 03 Iss. 03:15-19. https://doi.org/10.32439/ps.v3i3.15-19

Tang Z, Wang Y, Yang J, Xiao Y, Cai Y, Wan Y, Chen H, Yao H, Shan Z, Li C, Wang G. (2020). Isolation and identification of flavonoid-producing endophytic fungi from medicinal plant Conyza blinii H.Lév that exhibit higher antioxidant and antibacterial activities. PeerJ 8:e8978 . https://doi.org/10.7717/peerj.8978

Tarman K, Palm GJ, Porzel A, Merzweiler K, Arnold N, Wessjohann LA, Unterseher M, Lindequist U.(2012). Helicascolide $\mathrm{C}$, a new lactone from an Indonesian marine algicolous strain of Daldinia eschscholzii (Xylariaceae, Ascomycota). Phytochemistry Letters 5:83_86 DOI 10.1016/j.phytol.2011.10.006

Toghueo, R.M.K. (2020). Endophytes from Gingko biloba: the current status. Phytochem Rev 19, 743-759 . https://doi.org/10.1007/s11101-020-09679-4

Trung, H. V., Kuo, P. C., Tuan, N. N., Ngan, N. T., Trung, N. Q., Thanh, N. T., \& Wu, T. S (2019) Characterization of Cytochalasins and Steroids From the Ascomycete Daldinia concentrica and Their 
Cytotoxicity. Natural Product Communications, 14(5), 1934578X19846320.

https://doi.org/10.1177\%2F1934578X19846320

Weerasinghe,R.H., Attanayake,R.N., Weerakoon,G. and Paranagama,P.A (2020) Phylogenetic analysis and screening for biological potencies embodied in Endolichenic fungi residing in the lichens found in the mangrove eco-system of Negombo lagoon, Sri Lanka. NCBI GENBANK

Yang, T., Wang, C., Liu, H., Chou, G., Cheng, X., \& Wang, Z. (2010) A new antioxidant compound from Capparis spinosa. Pharmaceutical biology, 48(5), 589-594.

https://doi.org/10.3109/13880200903214231

Yurnaliza Yurnaliza, It Jamilah, Adrian Hartanto, Anisa Lut Fia (2021). Screening of endophytic fungi from oil palm (Elaeis guineensis) in producing exopolysaccharides. Biodiversitas. Vol 22, $1467-1473$. DOI: $10.13057 /$ biodiv/d220350

Zhang YL, Zhang J, Jiang N, Lu YH, Wang L, Xu SH, Wang W, Zhang GF, Xu Q, Ge HM, Ma J, Song YC, Tan RX. (2011). Immunosuppressive polyketides from mantis-associated Daldinia eschscholzii. Journal of the American Chemical Society 133:5931_5940 DOI 10.1021/ja110932p.

\section{Figures}
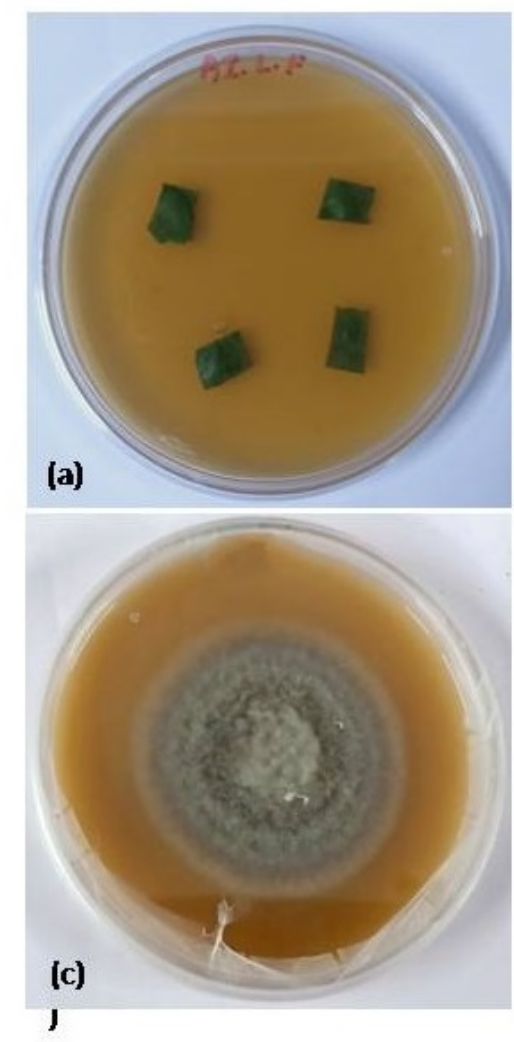
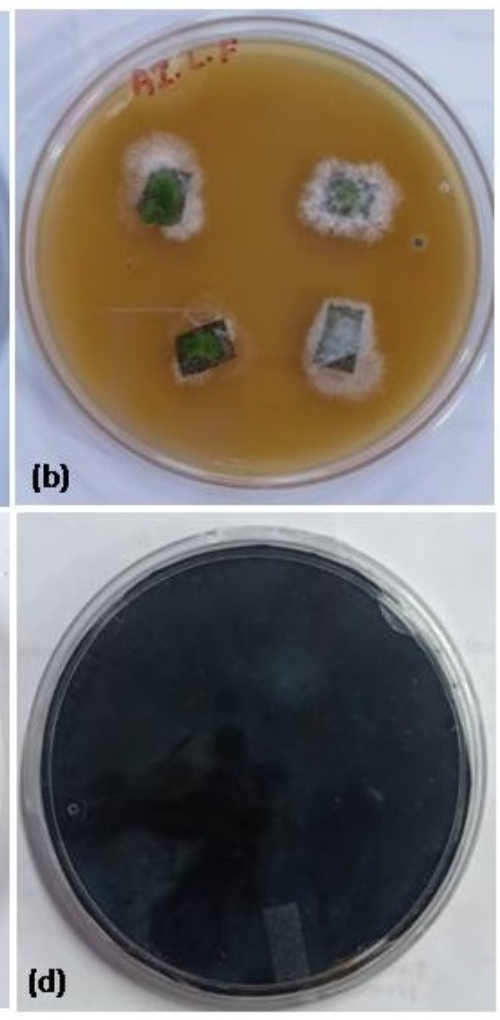

a
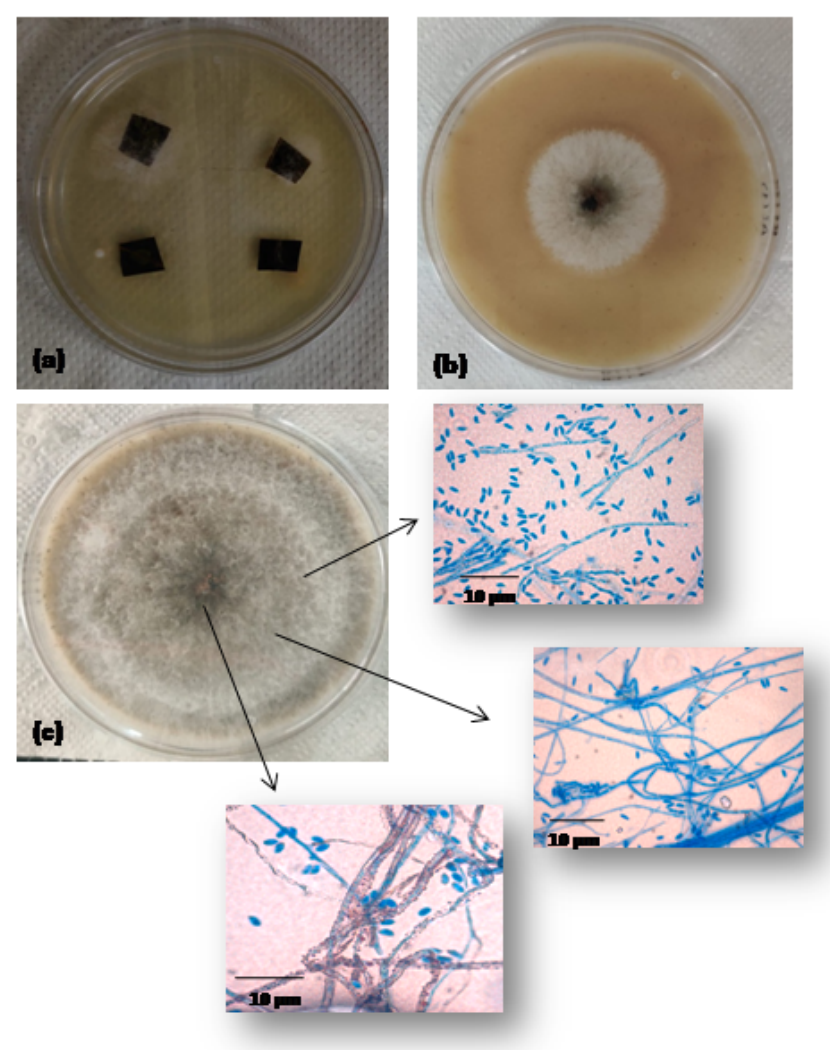

b

\section{Figure 1}


A Images of PDA plates containing endophytic fungi DE isolated from Al Leaf samples (a) Day 1- surface sterilized Al fresh leaves cut into $0.5 \times 0.5 \mathrm{~cm}$ (b) Day 3 - White cottony isolates grow on the surface of Al leaves (c) Day 12 - Sub cultured fungal isolate showing concentric circles - grey coloured mass (d) Black coloration on the reverse side of the completely grown DE fungal culture B Images of Oatmeal agar (OA) plates containing endophytic fungi DE isolated from Al Leaf samples (i) Day 3-surface sterilized Al leaves with White cottony isolates grow on the surface (ii) Day 7 - Sub cultured fungal isolate showing concentric circles (iii) Fully grown DE fungal culture and LCB stained culture showing conidia and coniophores with septate hyphae
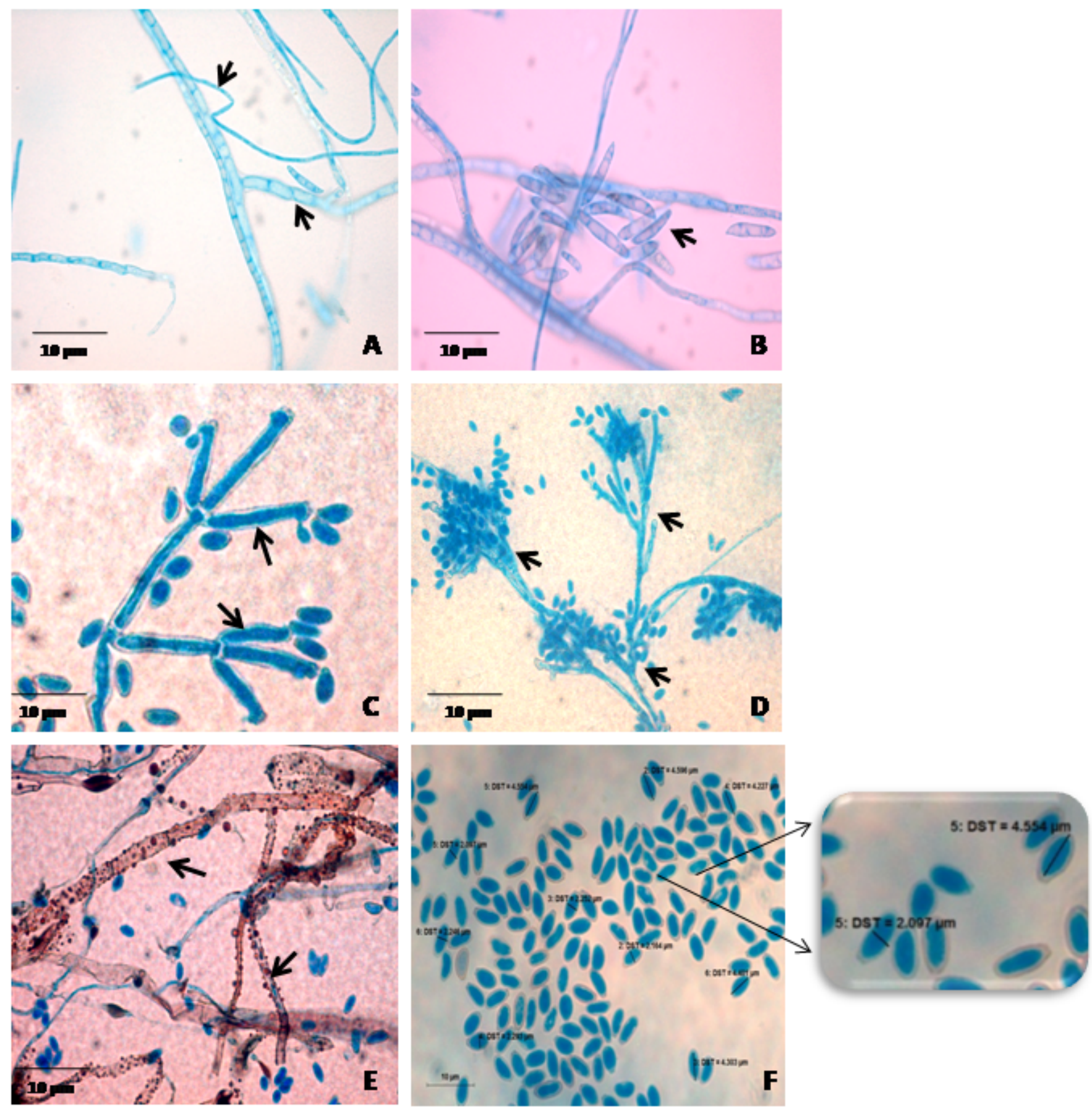

Figure 2 
Bright field microscopic imaging and identification of DE structures using Lactophenol cotton blue staining (A) Thin and thick walled septate Hyphae (B) Hyaline and cylindrical conidiogenous cells (C) Irregularly branched conidiophores with conidiogenous cells originating from the each ends (D)The septate conidiophores form dichotomous and trichotomous branches with clusters of conidia at the terminus (E) Brownish black exudates on the surface of thick walled hyphae (F) Hyaline conidia with ellipsoid and attenuated base - length $4.3-4.7 \mu \mathrm{m}$ and diameter $2.0-2.25 \mu \mathrm{m}$. Magnification-100X (oil immersion) Scale bar represents $50 \mu \mathrm{m}$

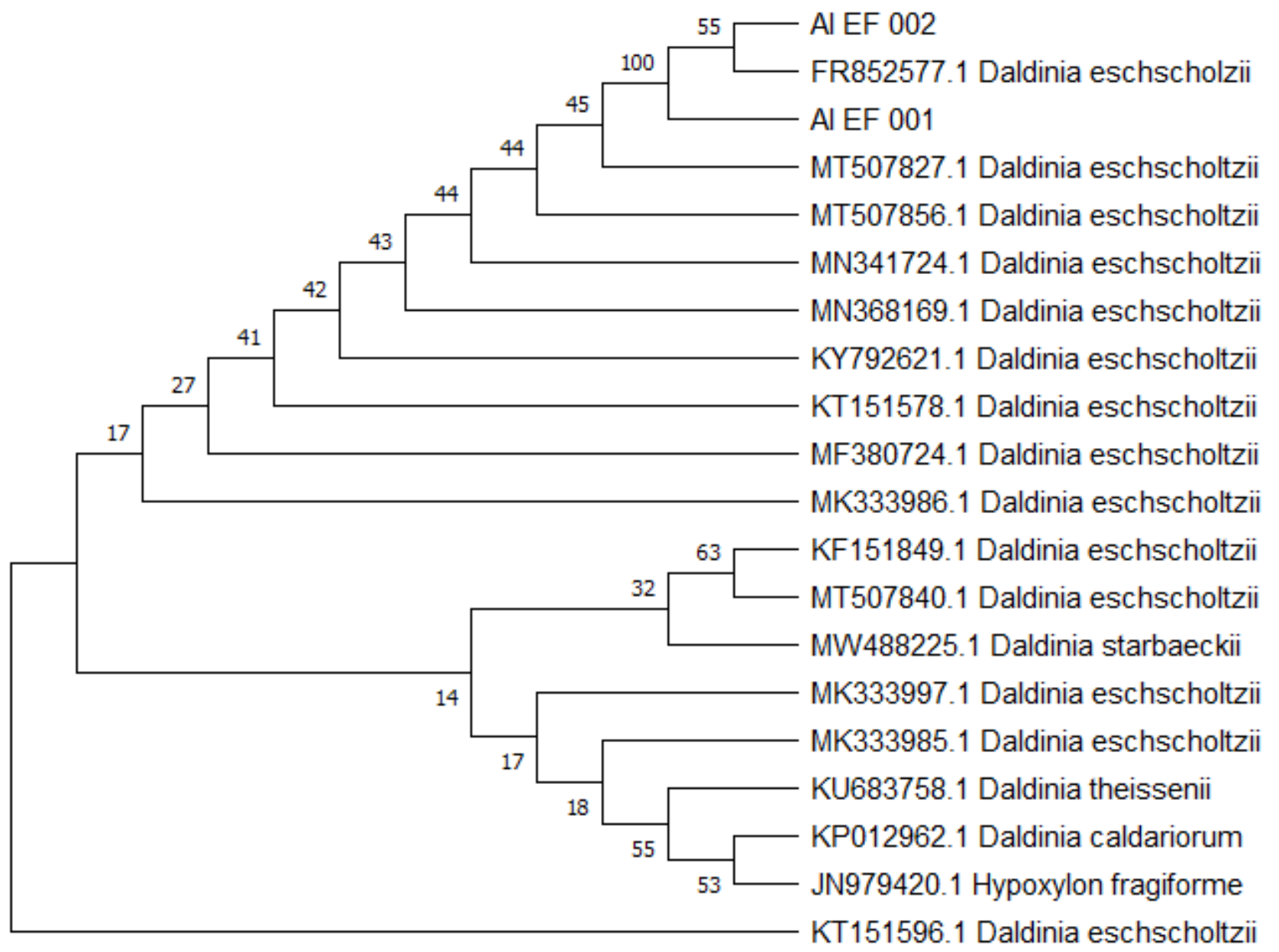

\section{Figure 3}

Phylogenetic consensus tree based on the Neighborhood joining $(\mathrm{NJ})$ analysis inferred from the nearest neighbors of endophytic fungi, DE isolated from Al with maximum Bootstrap values indicated above each branch. Hypoxylon fragiforme was used as outgroup. Both isolates AI.EF 001 and Al.EF 002 formed a cluster within the clade 


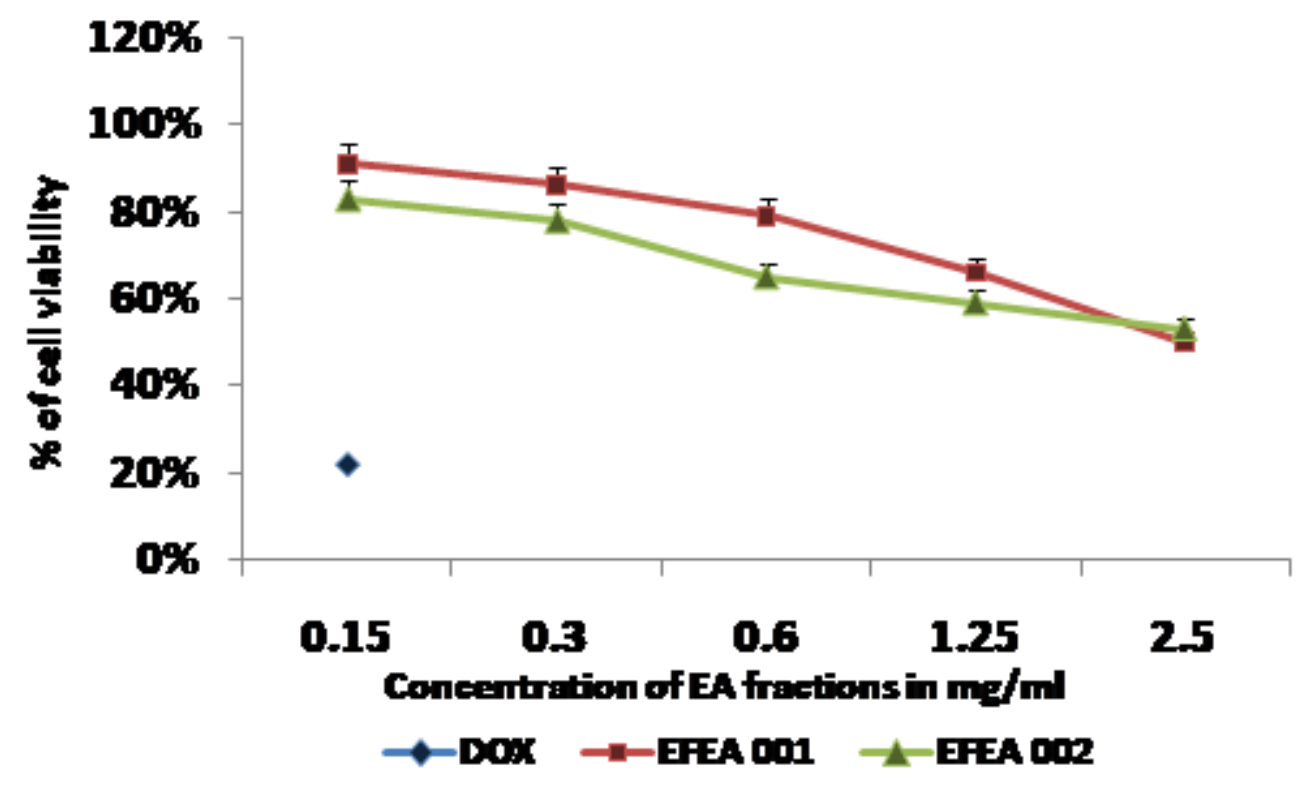

Figure 4

FACS/PI based cell viability of EFEA against AtT 20 cells. Comparative line graph of PI +ve cells expressed as percentage of total AtT 20 cells ${ }^{*} p<0.01$ 
<smiles>O=c1cc(-c2ccccc2)oc2c1ccc1ccccc12</smiles>

(a)

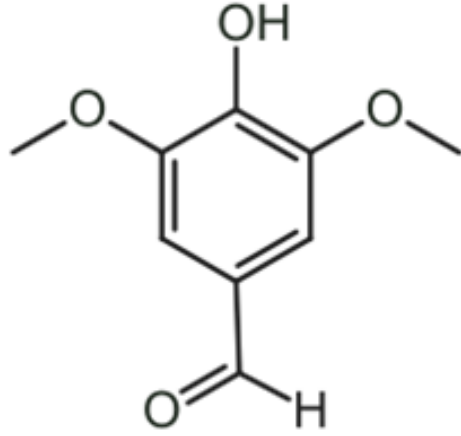

(b)

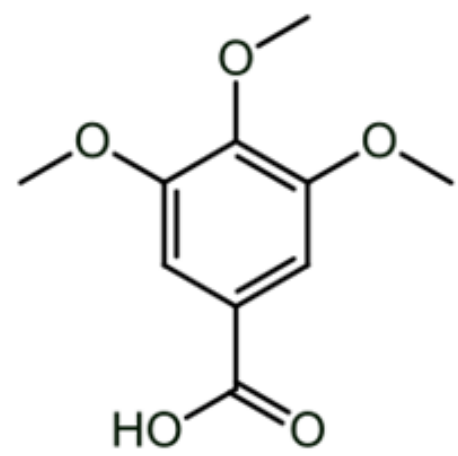

(c)

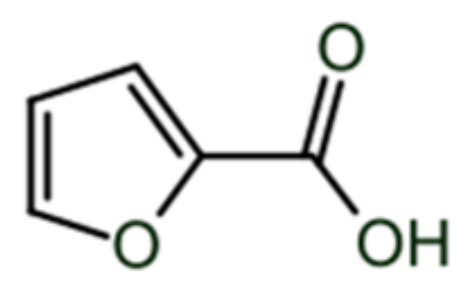

(d)

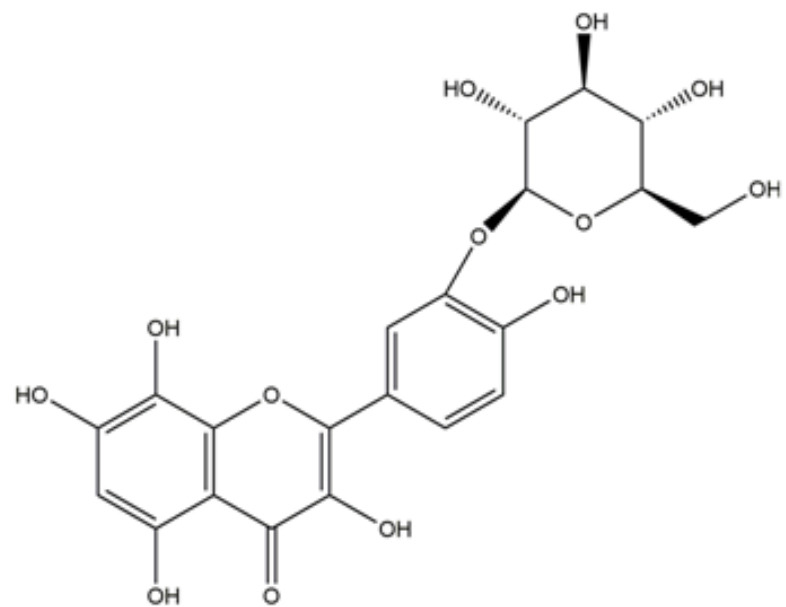

(e)

\section{Figure 5}

Structure of compounds C1-C5(a) C1- 》-napthoflavone, C2-Syringaldehyde, C3-3,4,5 trimethoxy benzoic acid, C4 - 2 Furoic acid, C5 - Gossypetin 3'O Glycoside 


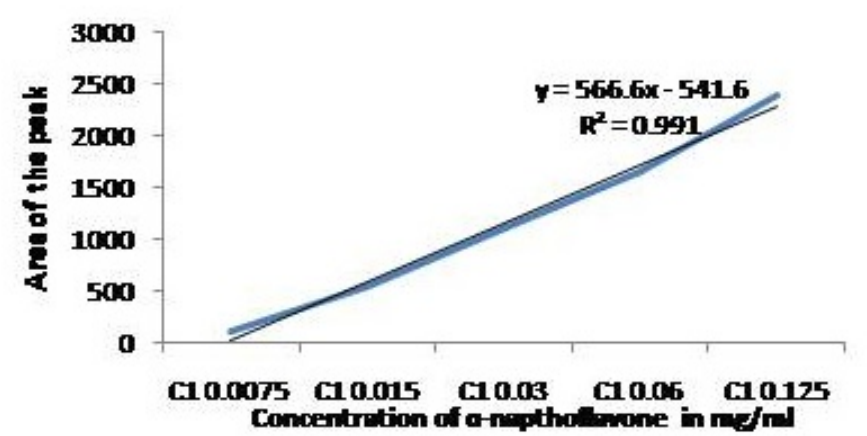

(a)

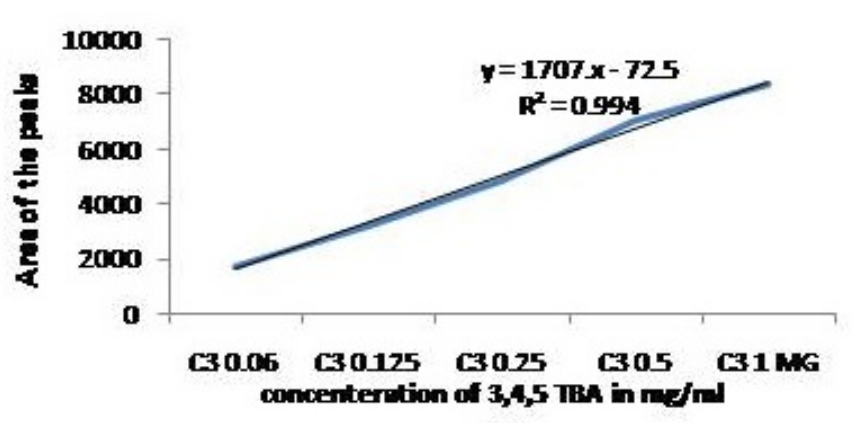

(c)

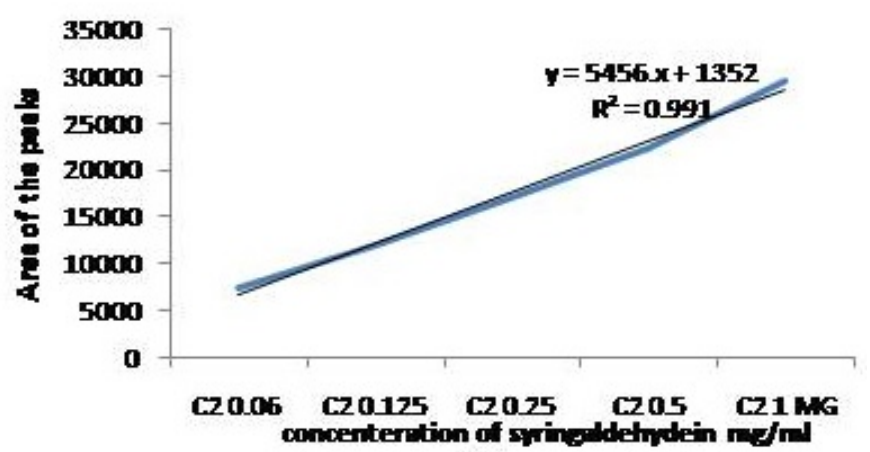

(b)

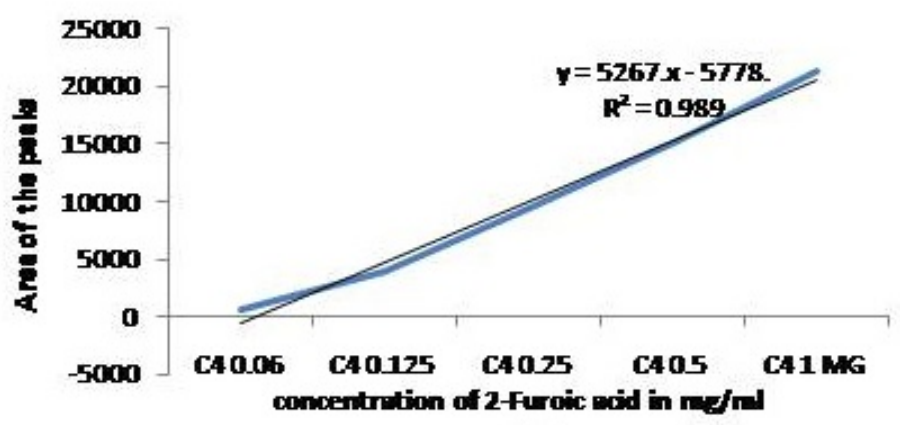

(d)

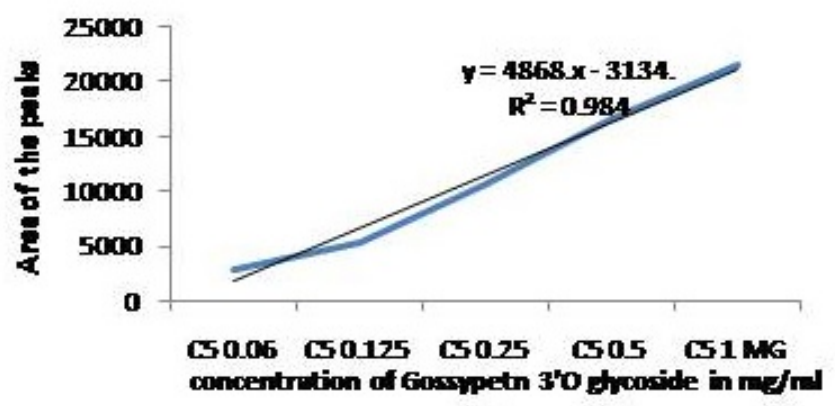

(e)

Figure 6

HPTLC Quantification -Calibration curve of compounds C1 - C5 in the EFEA fractions. (a) C1 - \napthoflavone (b) C2 - Syringaldehyde (c) C3 - 3,4,5 trimethoxy benzoic acid (d) 2-Furoic acid (e) C5 Gossypetin 3'O glycoside 


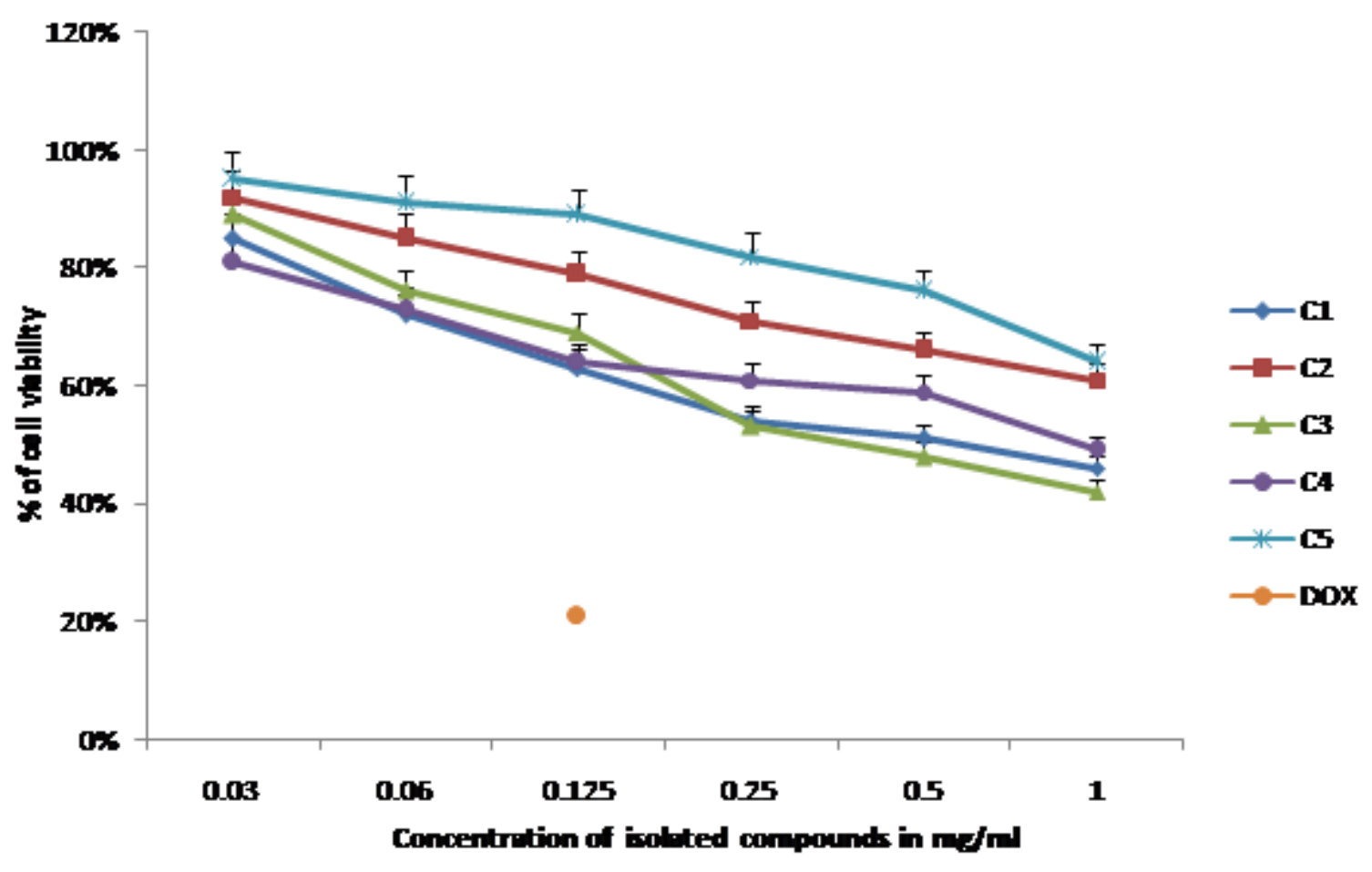

Figure 7

Determination of cell viability of compounds C1 - C5 against AtT 20 cells by MTT assay. Cells were treated with different concentrations of compounds C1-C5 $(1,0.5,0.25,0.06, \& 0.03 \mathrm{mg} / \mathrm{ml})$ respectively. Doxorubin $(0.1 \mathrm{mg} / \mathrm{ml})$ was used as positive control. Compounds $\mathrm{C} 1$ - C5 showed significant viability $(P<0.01)$ against AtT 20 cells. 


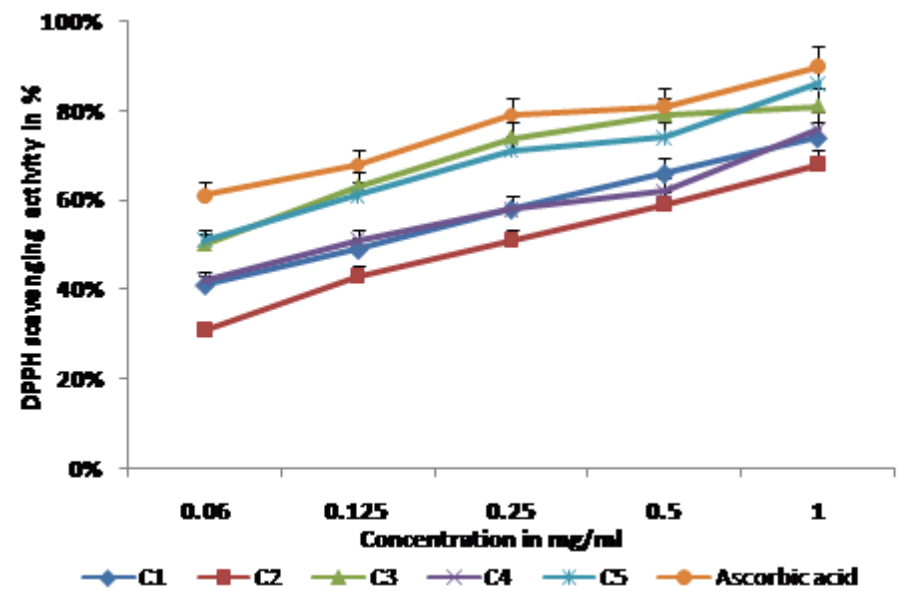

(a)

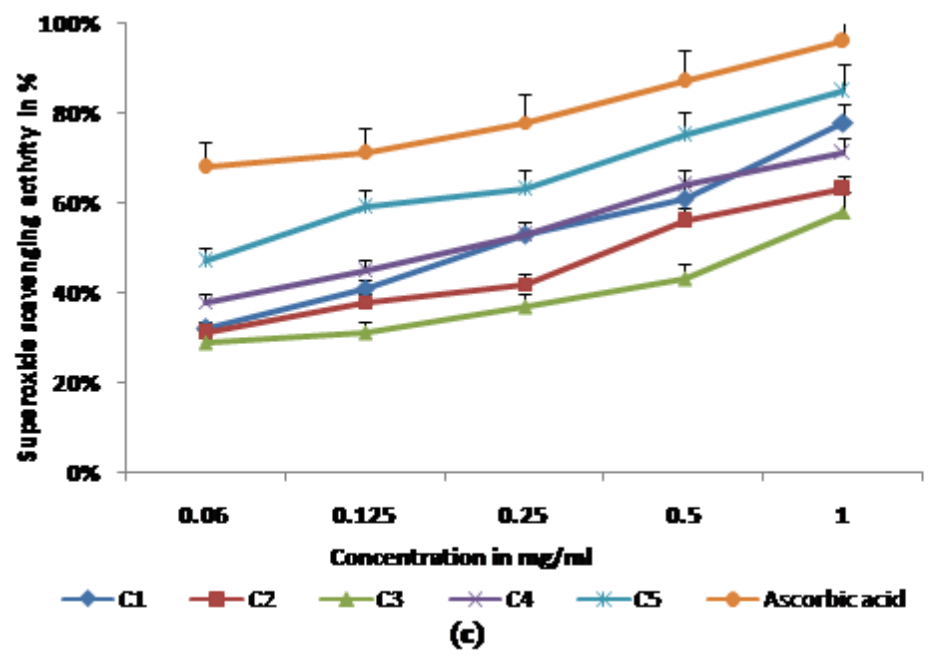

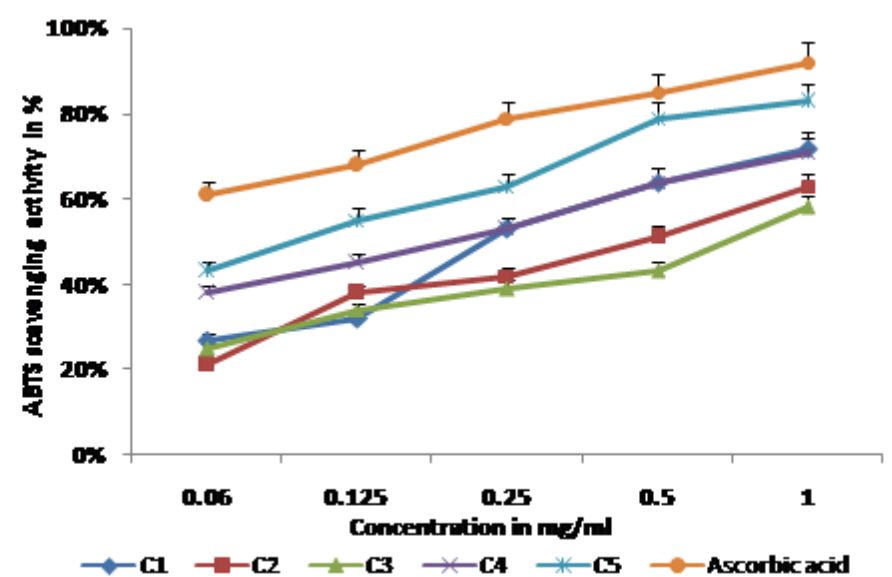

(b)

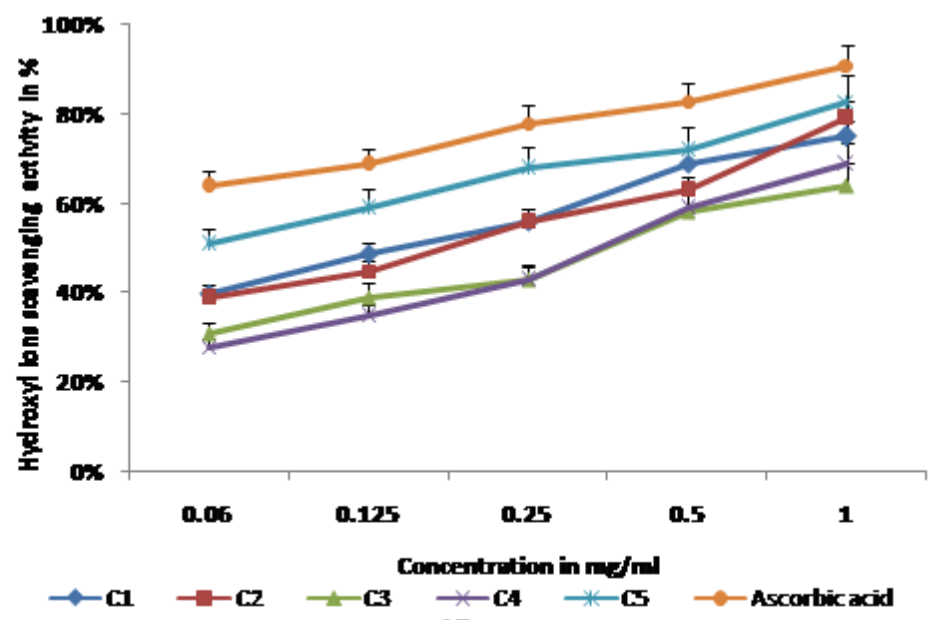

(d)

Figure 8

Radical scavenging activity of isolated compounds (a) DPPH radical scavenging activity (b) ABTS radical scavenging activity (c) Superoxide anion scavenging activity (d) Hydroxyl radical scavenging activity. All assays were compared to the standard antioxidant Ascorbic acid. ** $p<0.01$, 
(a)

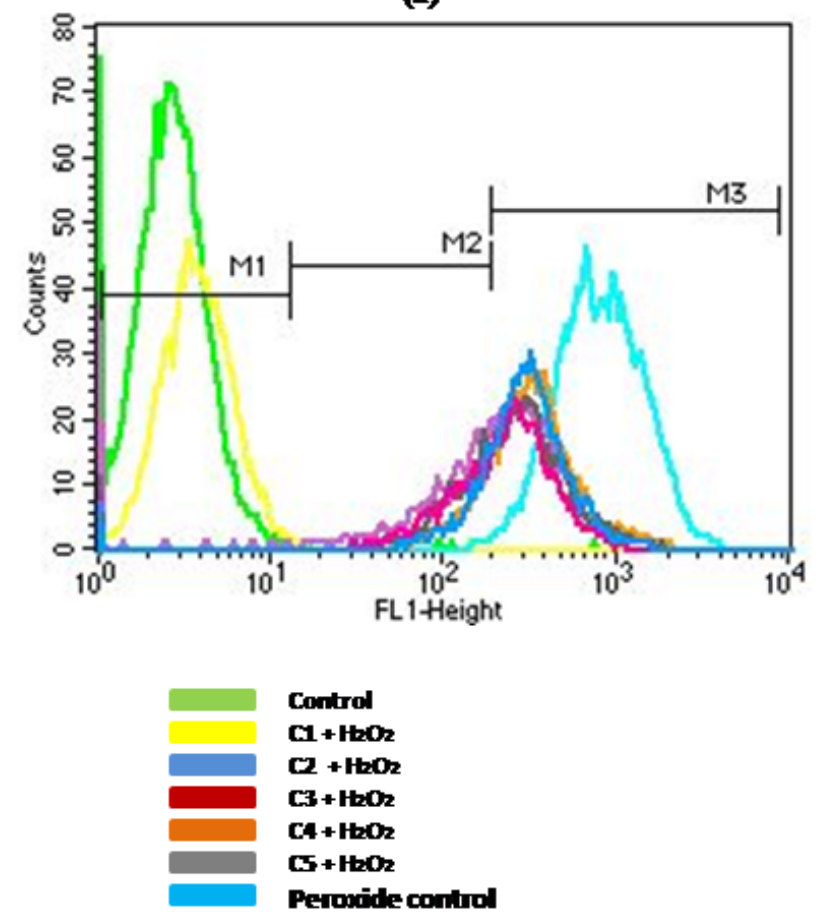

(b)

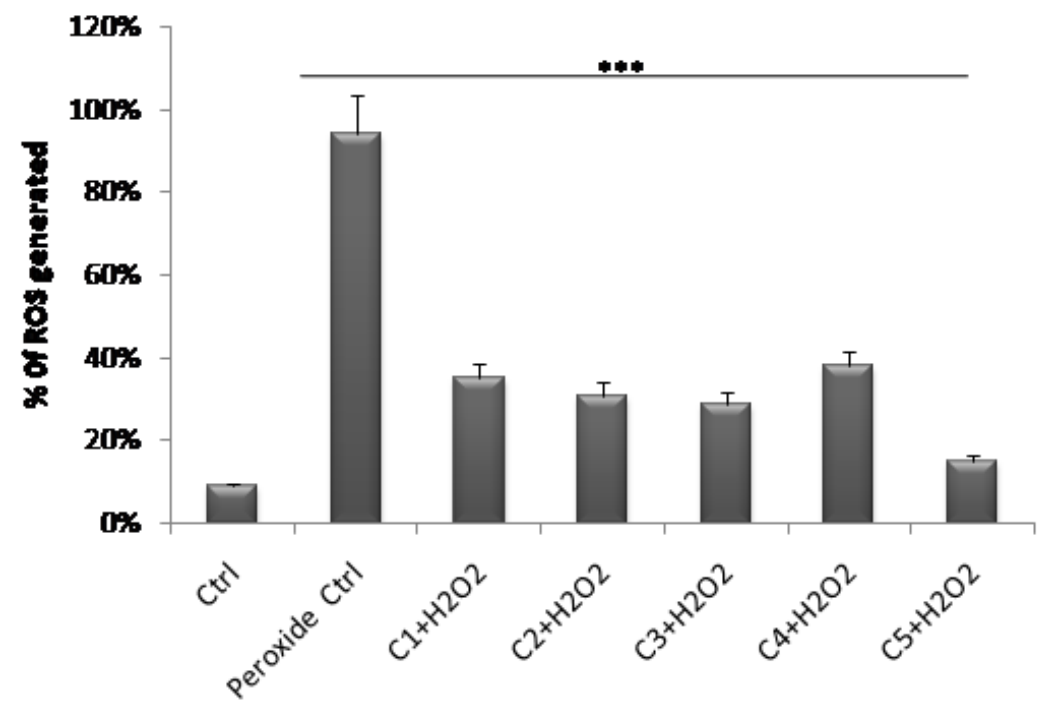

Figure 9

Intracellular ROS scavenging activity of compounds C1-C5 in AtT 20 cells (a) Overlay histogram plot showing the shift in fluorescence by DCFDA (b) Graphical representation of \% of ROS generated. ${ }^{* \star *} \mathrm{P}<$ 0.001 


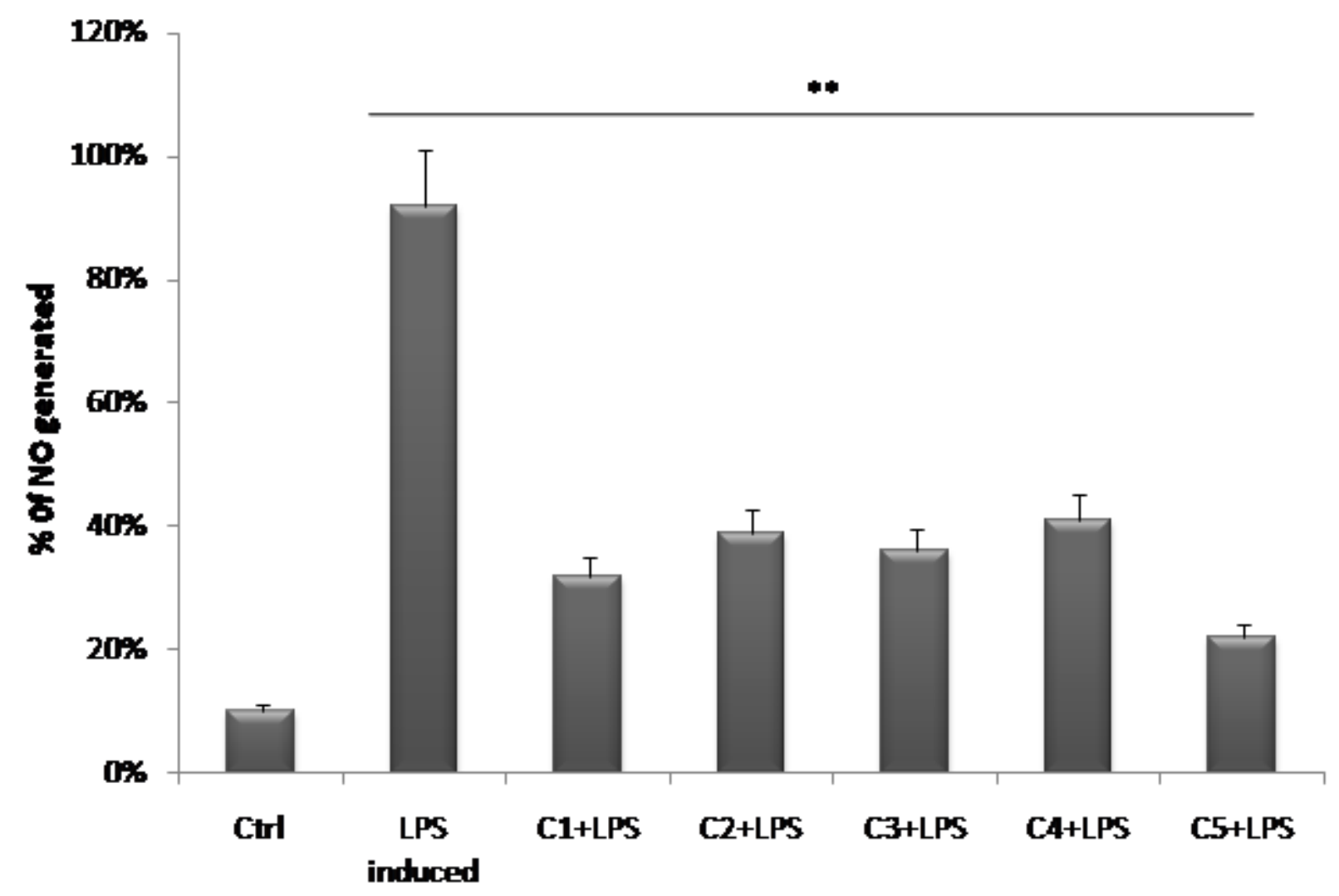

Figure 10

Graphical representation of LPS induced nitric oxide scavenging activity of compounds C1-C5 in AtT 20 cells. All the compounds showed significant reduction in the production of NO. ${ }^{\star *} p<0.01$ 


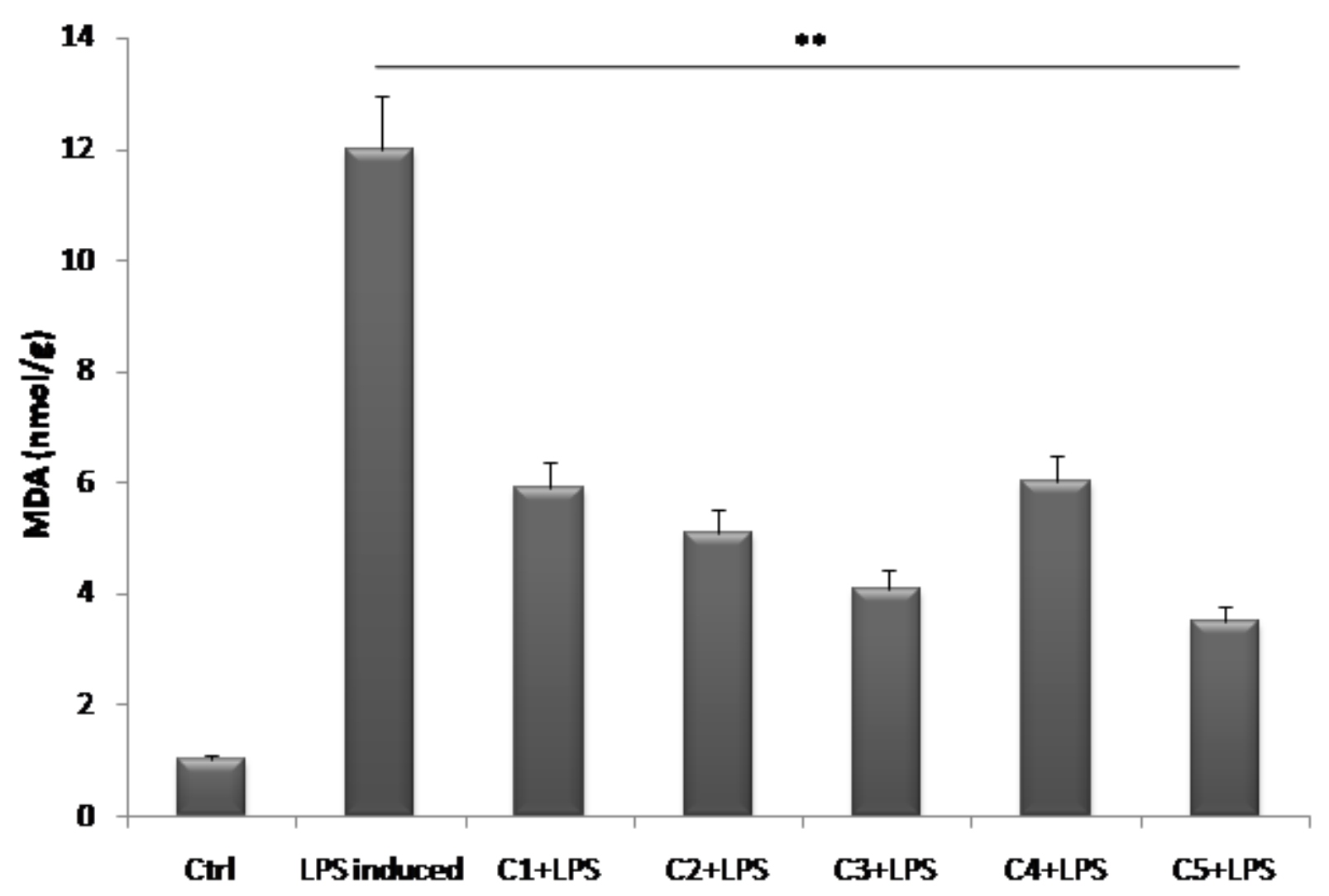

Figure 11

Graphical representation of inhibition of LPS induced lipid peroxidation by compounds C1-C5 in AtT 20 cells. All the compounds showed significant reduction in the production of the product MDA. Levels of MDA are represented in $\mathrm{nmol} / \mathrm{g} .{ }^{* *} \mathrm{p}<0.01$

\section{Supplementary Files}

This is a list of supplementary files associated with this preprint. Click to download.

- GRAPHICALABSTRACT.tif

- SUPPLEMENTARYMATERIAL.docX 